\title{
Reseña de Sentencias del Tribunal Constitucional sobre la Administración Local y Autonómica correspondientes al año 2003
}

\author{
Francisco Javier Fernández González \\ Director Jurídico Municipal del Ayuntamiento de Santander \\ Profesor Titular de Derecho Administrativo. Universidad de Oviedo
}

Sumario: I. DERECHO PARLAMENTARIO. II. COLEGIOS PROFESIONALES. III. EMPLEO PÚBLICO. IV. RÉGIMEN ELECTORAL. V. JURISDICCIÓN CONTENCIOSO-ADMINISTRATIVA. VI. ACTIVIDAD SANCIONADORA. VII. PROPIEDADES PÚBLICAS. VIII. DERECHO PÚBLICO DE LA ECONOMÍA: A) Comercio. B) Farmacias. C) Industria: subvenciones públicas del Estado IX. RECURSOS NATURALES.

\section{DERECHO PARLAMENTARIO}

1. Recurso de amparo contra Acuerdo, de 28-11-2000, de la Mesa del Parlamento Vasco, confirmado por Acuerdo, de 11-12-2000, por el que se inadmite a trámite una proposición no de ley del Grupo Parlamentario Popular sobre requerimiento al Tribunal Vasco de Cuentas Públicas en relación con la no presentación por el Gobierno Vasco del Proyecto de Ley de Presupuestos Generales de la Comunidad Autónoma para el ejercicio de 2001. Derecho fundamental a acceder en condiciones de igualdad a las funciones y cargos públicos: el acceso en condiciones de igualdad se extiende a la permanencia en el mismo y al desempeño de las funciones que les son inherentes; directa relación entre el derecho de un parlamentario a acceder a las funciones y cargos públicos con el derecho a la participación política en cuanto representantes de los ciudadanos; derecho de configuración legal: la configuración corresponde a los reglamentos parlamentarios; Cargo público representativo: estatus constitucional: tienen capacidad para reclamar la protección del «ius in officium» ante el TC por la vía de amparo: no cualquier acto que infrinja la legalidad del «ius in officium» resulta lesivo del derecho fundamental: a estos efectos, sólo poseen relevancia constitucional los derechos y facultades atribuidos al representante pertenecientes al núcleo de su función representativa parlamentaria.Mesas de las Cámaras: tienen atribuciones reglamentarias en orden a la calificación y admisión a trámite de iniciativas parlamentarias: les corresponde examinar si las iniciativas cumplen los requisitos formales exigidos por la norma reglamentaria, pudiendo extenderse más allá de la estricta verificación de los requisitos formales cuando la legalidad aplicable imponga límites materiales a las iniciativas. Parlamento Vasco: Mesa del Parlamento: Proposiciones no de ley: calificación y admisión a trámite: además de la verificación de los requisitos formales regla- 
mentarios, se extiende también al examen del contenido material de la iniciativa en cuanto resulte determinante para llevar a cabo un juicio de calificación sobre la idoneidad y procedencia del procedimiento parlamentario elegido; La Mesa tiene el deber de motivar expresa, suficiente y adecuadamente la aplicación de las normas cuando pueda resultar de la misma una limitación al ejercicio de aquellos derechos y facultades que integran el estatuto constitucionalmente relevante de los representantes políticos; Inadmisión a trámite por la Mesa: la causa implícita de inadmisión no tiene cobertura legal en la facultad de la Mesa de calificar y admitir o no a trámite las proposiciones no de ley: decisión que impide a los parlamentarios el ejercicio de las funciones que configuran su estatus representativo: vulneración existente del derecho a acceder en condiciones de igualdad a las funciones $y$ cargos públicos.

Fallo:

En atención a todo lo expuesto, el Tribunal Constitucional, ha decidido:

Estimar la presente demanda de amparo y, en su virtud:

$1^{\circ}$ Declarar el derecho de los parlamentarios integrantes del Grupo Parlamentario Popular en el Parlamento Vasco a ejercer sus cargos públicos en los términos que dimanan del art. 23.2 CE.

$2^{\circ}$ Anular el Acuerdo de la Mesa del Parlamento Vasco, de 8 de noviembre de 2000, por el que se inadmitió a trámite la proposición no de ley presentada por el Grupo Parlamentario Popular sobre requerimiento al Tribunal Vasco de Cuentas Públicas en relación con la no presentación por el Gobierno Vasco del proyecto de ley de presupuestos generales de la Comunidad Autónoma para el ejercicio de 2001, así como el Acuerdo de 11 de diciembre de 2000, por el que se desestimó la solicitud de reconsideración formulada contra el anterior Acuerdo.

(STC n. ${ }^{\circ} 40 / 2003$ (Sala Primera), de 27 febrero. Recurso de Amparo n. ${ }^{\circ}$ 1380/2001. Ponente: D. María Emilia Casas Baamonde).

\section{COLEGIOS PROFESIONALES}

1. Recurso de amparo $n^{\circ} 3782 / 2002$ contra la Sentencia de la Sección Undécima de la Audiencia Provincial de Valencia, de 16 de mayo de 2002, que desestimó el recurso de apelación interpuesto por el deman- 
dante, Secretario de la Administración local con habilitación de carácter nacional, y confirmó la sentencia dictada en la primera instancia que le condenó al pago de la cantidad reclamada por el Colegio de Secretarios, Interventores y Tesoreros de Administración local con habilitación de carácter nacional de la provincia de Valencia en concepto de impago de las cuotas colegiales. El recurrente imputa a la resolución judicial impugnada la vulneración del derecho a la libertad de asociación en su vertiente negativa (art. 22 CE) y del principio de igualdad (art. 14 CE). El TC estima parcialmente el amparo.

«El examen de la cuestión planteada requiere traer a colación la doctrina constitucional, perfilada más recientemente por el Pleno de este Tribunal en la STC 194/1998, de 1 de octubre, invocada por el Ministerio Fiscal, sobre la relación entre los colegios profesionales, la exigencia de la colegiación obligatoria y el derecho de asociación que garantiza el art. 22 CE (FF. 3 y 4), teniendo en cuenta que, en definitiva, los miembros del colegio puesto en cuestión son funcionarios públicos, que ejercen su actividad profesional exclusivamente en el ámbito de la Administración pública e integrados en una organización administrativa, por tanto, de carácter público, sin poder desempeñarla privadamente, siendo la propia Administración pública la destinataria inmediata de los servicios prestados por ellos (...).

En el presente supuesto, por lo tanto, la exigencia de colegiación obligatoria no se presenta como un instrumento necesario para la ordenación de la actividad profesional de los Secretarios, Interventores y Tesoreros de la Administración local con habilitación de carácter nacional a fin de garantizar el correcto desempeño de la misma y los intereses de quienes son los destinatarios de los servicios prestados por dichos profesionales.

Con base en las precedentes consideraciones ha de concluirse que la resolución judicial impugnada, al aceptar como dato determinante para la solución de la reclamación de cantidad objeto del proceso «a quo» la adscripción obligatoria del recurrente al Colegio de Secretarios, Interventores y Tesoreros de Administración local con habilitación de carácter nacional de la provincia de Valencia, lesionó el derecho a la libertad de asociación en su vertiente negativa (art. $22 \mathrm{CE}$ ), lo que conduce a la anulación de dicha Sentencia» (vid. f.j 3).

«Finalmente, el demandante de amparo considera que también ha resultado vulnerado el principio de igualdad (art. $14 \mathrm{CE}$ ), dado que la colegiación obligatoria de los Secretarios, Interventores y Tesoreros de la Administración local no es exigida en todas las Comunidades Autónomas, pues 
en la normativa de algunas de ellas se excepciona el cumplimiento de tal requisito en relación con los funcionarios o personal que preste servicios en sus Administraciones.

Sin necesidad de entrar en otro tipo de consideraciones, es suficiente para desestimar en este extremo la queja del recurrente en amparo con recordar, como este Tribunal ya tiene declarado, que el principio constitucional de igualdad no impone que todas las Comunidades Autónomas ostenten las mismas competencias, ni, menos aún, que tengan que ejercerlas de una manera o con un contenido y unos resultados idénticos o semejantes, pues la autonomía significa precisamente la capacidad de cada Comunidad para decidir cómo ejercer sus propias competencias, en el marco de la Constitución y del Estatuto, y si, como es lógico, de dicho ejercicio derivan desigualdades en la posición jurídica de los ciudadanos residentes en cada una de las distintas Comunidades Autónomas, no por ello resulta necesariamente infringido el principio de igualdad (art. 14 $\mathrm{CE}) »\left(\right.$ vid. f.j. $\left.4^{\circ}\right)$.

Fallo: Estimar parcialmente la demanda de amparo y, en su virtud:

$1^{\mathrm{o}}$ Reconocer el derecho del recurrente en amparo a la libertad de asociación (art. $22 \mathrm{CE}$ ), en su vertiente negativa.

$2^{\circ}$ Declarar la nulidad de la Sentencia dictada en apelación por la Sección Undécima de la Audiencia Provincial de Valencia n. ${ }^{\circ}$ 236/2002, de 16 de mayo de 2002, y de la dictada por el Juzgado de Primera Instancia n. ${ }^{\circ}$ 2 de Onteniente el 15 de diciembre de 2001.

$3^{\circ}$ Desestimar la demanda de amparo en todo lo demás.

[Sentencia del Tribunal Constitucional n..$^{\circ}$ 217/2003 (Sala Primera), de 1 diciembre. BOE 8-1-2004. Ponente: J. Rodríguez-Zapata Pérez [en sentido similar: STC n. ${ }^{\circ}$ 227/2003 (Sala Primera), de 15 diciembre. BOE 201-2004. Ponente: P. García Manzano; STC n. ${ }^{\circ} 226 / 2003$ (Sala Primera), de 15 diciembre. BOE 20-1-2004. Ponente: J. Rodríguez-Zapata Pérez; STC n. ${ }^{\circ}$ 210/2003 (Sala Primera), de 1 diciembre. BOE 8-1-2004. Ponente: R. García-Calvo y Montiel; STC n. ${ }^{\circ}$ 216/2003 (Sala Primera), de 1 diciembre. BOE 8-1-2004. Ponente: J. Rodríguez-Zapata Pérez; STC n. ${ }^{\circ}$ 201/2003 (Sala Primera), de 10 noviembre. BOE 11-12-2003. Ponente: R. García-Calvo y Montiel; STC n. ${ }^{\circ}$ 183/2003 (Sala Segunda), de 20 octubre. BOE 13-11-2003. Ponente: P.M. Cachón Villar; STC n. ${ }^{\circ}$ 162/2003 (Sala Primera), de 15 septiembre. BOE 9-10-2003. Ponente: M. Jiménez 
de Parga y Cabrera; STC n. ${ }^{\circ}$ 149/2003 (Sala Primera), de 14 julio. BOE 13-08-2003. Ponente: M. Jiménez de Parga y Cabrera; STC n. ${ }^{\circ}$ 120/2003 (Sala Primera), de 16 junio. BOE 17-07-2003. Ponente: M. Jiménez de Parga y Cabrera; STC n. ${ }^{\circ}$ 108/2003 (Sala Segunda), de 2 junio. BOE 107-2003. Ponente: G. Jiménez Sánchez; STC n. ${ }^{\circ}$ 96/2003 (Sala Primera), de 22 mayo. BOE 10-06-2003. Ponente: M. E. Casas Baamonde; STC n. ${ }^{\circ}$ 76/2003 (Pleno), de 23 abril. BOE 17-05-2003. Ponente: V. Conde Martín de Hijas].

\section{EMPLEO PÚBLICO}

1. Cuestión de inconstitucionalidad planteada por la Sección Séptima de la Sala de lo Contencioso-Administrativo del Tribunal Superior de Justicia de Madrid, en relación con el art. 20 de la Ley de la Asamblea de Madrid 15/1991, de 13 diciembre, de Presupuestos Generales de la Comunidad de Madrid para 1991 (Votos particulares formulados, el primero, por el magistrado don Vicente Conde Martín de Hijas, y el segundo, por el magistrado don Jorge Rodríguez-Zapata Pérez, al que se adhieren el presidente, don Manuel Jiménez de Parga y Cabrera y el magistrado don Roberto García-Calvo y Montiel). Vulneración inexistente de los límites materiales del contenido constitucional de las leyes de presupuestos, de la competencia del Estado en materia de legislación básica del régimen estatutario de los funcionarios públicos y del principio de igualdad ante la ley en relación con los principios constitucionales de mérito y capacidad. Retribuciones: grado personal máximo: consolidación por funcionarios de carrera y estatutarios que desempeñen o hayan desempeñado altos cargos: naturaleza: compensación económica sin ninguna consecuencia en la carrera profesional: finalidad de carácter eminentemente económico: no se contempla un derecho de los funcionarios a la consolidación de un grado personal máximo, igual o superior al nivel 30, sino exclusivamente un simple beneficio retributivo que no pone en entredicho el esquema de grados personales previsto en la legislación estatal básica.

Fallo:

En atención a todo lo expuesto, el Tribunal Constitucional, ha decidido desestimar la presente cuestión de inconstitucionalidad.

(STC n. ${ }^{\circ}$ 202/2003 (Pleno), de 17 noviembre. Cuestión de Inconstitucionalidad n. ${ }^{\circ}$ 4783/1999. Ponente: D. María Emilia Casas Baamonde). 
2. Conflicto positivo de competencia promovido por el Consejo Ejecutivo de la Generalidad de Cataluña, en relación con la Orden de 4-51995, del Ministerio para las Administraciones Públicas, por la que se aprueban las bases reguladoras de la concesión de ayudas para el desarrollo de planes de formación en el marco del Acuerdo de formación continua en las administraciones públicas de 28-03-1995, y su aplicación por las Resoluciones del Instituto Nacional de Administración Pública (INAP) de 04-05-1995 y 20-05-1995. Título competencial aplicable: bases del régimen estatutario de los funcionarios públicos; Subvenciones del Estado: concesión por el Instituto Nacional de Administración Pública (INAP): vulneración de competencias de la Generalidad de Cataluña: necesaria territorialización en favor de las Comunidades Autónomas de la financiación que a cada una le corresponda: la concesión compete a la Generalidad de Cataluña cuando se trate de sus funcionarios públicos: no procede la excepcional gestión centralizada, ni la aplicación del art. 149.1.1 ${ }^{a}$ CE: tampoco procede el informe preceptivo vinculante de un órgano del Estado; vulneración de las competencias de la Comunidad Autónoma al haberse condicionado la remisión a una resolución previa del INAP.

Fallo:

En atención a todo lo expuesto, el Tribunal Constitucional, ha decidido Estimar parcialmente el conflicto positivo de competencia n. ${ }^{\circ} 3342 / 95$, promovido por el Consejo Ejecutivo de la Generalidad de Cataluña contra la Orden de 4 de mayo de 1995, del Ministerio para las Administraciones Públicas, por la que se aprueban las bases reguladoras de la concesión de ayudas para el desarrollo de planes de formación en el marco del Acuerdo de formación continua en las Administraciones públicas de 28 de marzo de 1995, y su aplicación por las Resoluciones del Instituto Nacional de Administración Pública de 4 y 30 de mayo de 1995, mediante las que se efectúa la primera y segunda convocatoria, respectivamente, para el ejercicio de 1995 de concesión de ayudas en el marco del citado Acuerdo, y, en consecuencia, declarar que vulneran las competencias de la Generalidad de Cataluña:

$1^{\circ}$ Los arts. 1.3 y 2 a) de la Orden de 4 de mayo de 1995.

$2^{\circ}$ Las Resoluciones del Instituto Nacional de Administración Pública de 4 de mayo y 30 de mayo de 1995, en tanto se refieran a los planes de formación de los funcionarios propios de la Generalidad de Cataluña. 
RESEÑA DE SENTENCIAS DEL TRIBUNAL CONSTITUCIONAL SOBRE LA ADMINISTRACIÓN LOCAL Y AUTONÓMICA...

$3^{\circ}$ Desestimar el conflicto positivo de competencia en todo lo demás.

(STC n. ${ }^{\circ}$ 228/2003 (Pleno), de 18 diciembre. Conflicto positivo de competencia n. ${ }^{\circ}$ 3342/1995. Ponente: D. Tomás S. Vives Antón).

3. Recurso de inconstitucionalidad promovido por el Gobierno de la Nación en relación con determinados incisos de los arts. 13, 17 y 19 de la Ley de la Asamblea de Extremadura 5/1995, de 20 abril, de modificación parcial y urgente del Texto Refundido de la Ley de la Función Pública de Extremadura, aprobado por Decreto Legislativo 1/1990, de 26 julio (con voto particular que formulan los magistrados don Manuel Jiménez de Parga y Cabrera, don Javier Delgado Barrio y don Jorge RodríguezZapata Pérez): Competencias de la Comunidad Autónoma de Extremadura en materia de funcionarios: competencia de desarrollo legislativo y ejecución de la legislación básica del Estado; Situaciones administrativas: excedencia voluntaria por agrupación familiar y excedencia forzosa: regulación autonómica que prevé como consecuencias, en determinadas circunstancias, la pérdida de la condición de funcionario: normativa que deviene inconstitucional por contraria a la posterior modificación de la legislación básica. Competencia del Estado exclusiva para el establecimiento de las bases del régimen estatutario de los funcionarios públicos: se extiende a los aspectos relativos a la pérdida de la condición de funcionario y a las situaciones administrativas; determinación de la vigente normativa básica y no básica en cuanto a estos aspectos. Juicio de constitucionalidad de las leyes: parámetro de constitucionalidad: modificación de la legislación básica del Estado con posterioridad a la normativa autonómica: inconstitucionalidad sobrevenida de ésta; Sentencia: efectos: ley estatal posterior a la norma autonómica objeto de recurso: efectos a partir de la entrada en vigor de la ley estatal modificante.

Fallo:

En atención a todo lo expuesto, el Tribunal Constitucional, ha decidido:

Estimar el presente recurso de inconstitucionalidad y, en su virtud, declarar:

$1^{\circ}$ Que es inconstitucional y nulo el inciso «falta de petición de reingreso al servicio activo durante el período de duración de la excedencia voluntaria... por agrupación familiar» de la letra f) del artículo 35 del texto refundido de la Ley de la función pública extremeña, aprobado por Decreto Legislativo 1/1990, de 26 de julio, en la redacción dada a dicha letra 
por el art. 13 de la Ley de la Asamblea de Extremadura 5/1995, de 20 de abril, de modificación parcial y urgente del texto refundido de la Ley de la función pública de Extremadura.

$2^{\circ}$ Que es inconstitucional y nulo el párrafo segundo de la letra b) del art. 39.2.B del texto refundido de la Ley de la función pública extremeña, aprobado por Decreto Legislativo 1/1990, de 26 de julio, en la redacción dada a dicho párrafo por el art. 17 de la Ley de la Asamblea de Extremadura 5/1995, de 20 de abril, de modificación parcial y urgente del texto refundido de la Ley de la función pública de Extremadura, al establecer que: «La falta de petición de reingreso al servicio activo al finalizar el período máximo de excedencia por agrupación familiar o cuando desaparezcan las causas que dieron lugar a su concesión, comportará la pérdida de la condición de funcionario».

$3^{\circ}$ Que es inconstitucional y nulo el último inciso del art. 40.5 del texto refundido de la Ley de la función pública extremeña, aprobado por Decreto Legislativo 1/1990, de 26 de julio, en la redacción dada a dicho inciso por el art. 19 de la Ley de la Asamblea de Extremadura 5/1995, de 20 de abril, de modificación parcial y urgente del texto refundido de la Ley de la función pública de Extremadura, en cuanto dispone que: «Los demás funcionarios en excedencia forzosa, cuando incumplan las obligaciones mencionadas, perderán la condición de funcionario»».

(STC n. ${ }^{\circ} 1 / 2003$ (Pleno), de 16 enero. Recurso de Inconstitucionalidad n. ${ }^{\circ}$ 2987/1995. Ponente: D. María Emilia Casas Baamonde).

\section{RÉGIMEN ELECTORAL}

1. Recurso de amparo electoral $n .^{\circ} 5994 / 2003$ interpuesto en nombre $y$ representación de la agrupación de electores «Herri Taldea», contra la Sentencia de la Sala Especial del art. 61 LOPJ del Tribunal Supremo de 5 de octubre de 2003, dictada en el recurso número 6/200, interpuesto contra el Acuerdo de la Junta Electoral de Zona de Pamplona, de 29 de septiembre de 2003, por el que se deniega la candidatura de dicha agrupación al Concejo de Astiz, Ayuntamiento de Larráun (Navarra). Agrupaciones de electores que supuestamente vendrian a continuar o suceder la actividad de un partido político declarado judicialmente ilegal o disuelto, o suspendido. Se alega vulneración del arts.14, 16, 23.1 y 24.1 y 2 CE. El TC otorga el amparo.

«(...)Lo primero que cabe constatar es que resulta manifiesto que la Junta Electoral, al adoptar la decisión de no proclamar la candidatura de 
la agrupación aquí recurrente, lo hizo, tal y como en su literalidad hemos trascrito en el fundamento primero, fundándose exclusivamente en la Sentencia del Tribunal Supremo de mayo pasado, que, como ha quedado dicho, excluyó de la contienda electoral a la candidatura encabezada por quien ahora es componente único de la que presenta la agrupación que impetra el amparo. Recurrida en la vía contencioso-electoral tal decisión, la Sala que dictó la Sentencia aquí impugnada ha concluido que también esta agrupación «es continuadora o sucesora, de hecho, de los partidos políticos ilegalizados y disueltos por la Sentencia de 27 de marzo de 2003» (fundamento de Derecho octavo), previa ponderación -en coincidencia con el Ministerio Fiscal y el Abogado del Estado personados en el proceso- del «sentido que debe darse al hecho de que se concentre en una sola persona la propuesta formulada por la Agrupación Electoral, expresiva del grado máximo de identificación y vinculación con el único candidato por parte de los partidos políticos disueltos», de modo que ello «permite razonablemente inferir que los motivos y la coyuntura que se tuvo en consideración en las Sentencias de esta Sala de 3 de mayo de 2003 y por el propio Tribunal Constitucional (existencia de una estrategia común, incorporación de candidatos que cuantitativa y cualitativamente estaban vinculados a los partidos políticos ilegalizados, entre otros) siguen, en gran medida, subsistentes en la actualidad, en este caso concentrados en la persona del único miembro de la candidatura» (fundamento de Derecho séptimo).

Son estas argumentación y conclusión las que niega reiteradamente la actora, alegando al respecto, entre otras cosas, que ninguno de los comparecientes en la formación de la agrupación están afectados por la disolución de las formaciones políticas ilegalizadas, y, en definitiva, que: «No se da en nuestra Agrupación ninguno de los supuestos de continuidad previstos en el art. 44.4 de la LO 5/1985, ni ninguna similitud sustancial en personas, estructura, organización, funcionamiento, financiación... con los partidos políticos ilegalizados y disueltos por la Sentencia del Tribunal Supremo de 27-3-2003». Así las cosas resulta evidente que el punto de controversia en el caso es el carácter, suficiente o no, de la probanza en orden a concluir la sucesión o continuación de las formaciones políticas ilegalizadas por la agrupación recurrente. Pues bien, es claro que, en el caso, el único indicio disponible del que se ha deducido tal continuidad o sucesión es la presencia del candidato único de la agrupación a Presidente de Concejo abierto en una lista excluida de las anteriores elecciones municipales e integrando otra de uno de los partidos disueltos en las municipales de 1999. Ningún otro elemento ha sido tomado en consideración por la Junta Electoral que denegó la proclamación de la candidatura ni por la Sala que conoció del contencioso electoral subsiguiente, ni 
siquiera, según dijimos en nuestra STC 85/2003, la naturaleza y relevancia de la vinculación de la agrupación con las formaciones ilegalizadas, o el desempeño por alguno de sus componentes de cargos públicos relacionados con los partidos disueltos, o la existencia de condenas penales (F. 29); en definitiva, en el caso no ha existido «una pluralidad de magnitudes y referencias», o «no concurren acumuladamente una serie de factores» (Ibídem).

Siendo ello así, ha de concluirse que la exclusiva referencia a las aludidas circunstancias de quien conforma la candidatura de la agrupación recurrente para excluirla de la proclamación, necesariamente se convierte en una especie de inhabilitación del mismo para concurrir a las elecciones, es decir, se afecta directamente su derecho al sufragio pasivo, cuando, como hemos dicho en la tan mencionada STC 85/2003, el sentido constitucionalmente conforme del precepto electoral en cuya virtud la Junta Electoral de Zona primero y el Tribunal Supremo después excluyen la posibilidad de que la agrupación de electores aquí recurrente se presente a las elecciones, el art. 44.4 LOREG, «no es el propio de una causa restrictiva del derecho de sufragio pasivo, sino el de un mecanismo de garantía institucional con el que pretende evitarse, justamente, la desnaturalización de las agrupaciones electorales como instrumentos de participación ciudadana» (F. 24). En efecto, en la misma Sentencia y fundamento decimos que «Trasladar las consecuencias de la disolución de un partido del que se demuestre su condición de mera continuación del disuelto entra dentro de lo inevitable si no se quiere propiciar conductas fraudulentas. Ahora bien, trasladarlas, sin más, a las agrupaciones de electores supondría convertir la disolución de una persona jurídica en causa limitativa del ejercicio de un derecho fundamental por parte de personas físicas. Estas, además, quedarían afectadas en su derecho de sufragio pasivo por el solo hecho de haber tenido relación con el partido disuelto. La disolución del partido se convertiría en una suerte de «causa de inelegibilidad parcial». Semejante mutilación o restricción de su derecho «ex» art. 23.1 CE traería causa de una disolución acordada en función de la conducta acreditada de un partido político. Esto es, los hechos imputables a un partido se convertirían en causa de inelegibilidad de un particular a partir de la presunción de que éste continuará aquella línea de conducta. Una disolución basada en hechos probados pasaría a ser causa de la privación de un derecho a partir de la presunción de que el afectado realizará hechos de la misma especie. Se castigaría al particular y se le castigaría a partir de un juicio de intenciones. Algo que no puede justificar la disolución de un partido sí podría, en cambio, limitar el derecho de quien estuvo afiliado al partido cuando éste era legal». 
Pues bien, el efecto que se produce en este caso, conduce a un resultado que no puede ser admitido, en cuanto supone la vulneración de un derecho fundamental constitucionalmente garantizado, pues, como hemos dicho, «la disolución de un partido político [la vinculación respecto del cual por el único candidato de la agrupación recurrente es el indicio exclusivamente apreciado en el caso para excluir a dicha agrupación de su posibilidad de concurrir a los comicios] no comporta la privación del derecho de sufragio, activo o pasivo, de quienes fueron sus promotores, dirigentes o afiliados. Semejante consecuencia sólo puede traer causa de un procedimiento judicial específicamente centrado en la conducta o en las circunstancias de personas físicas, quienes, en los términos previstos por la Ley, únicamente pueden verse privadas del ejercicio del derecho fundamental reconocido en el art. 23.1 CE si concurren las causas también taxativamente fijadas... entre las que no figura la vinculación con un partido disuelto» (STC 85/2003, F. 23, que aplica el F. 19 de la Sentencia de este Tribunal 48/2003, de 12 de marzo). (vid. f.j. 5)

Fallo: Se acuerda otorgar el amparo solicitado y, en consecuencia:

$1^{\circ}$ Declarar que la agrupación de electores «Herri Taldea» ha visto vulnerado su derecho a la participación política (art. $23 \mathrm{CE}$ ).

$2^{\circ}$ Restablecerla en la integridad de su derecho y, a tal fin, anular la Sentencia dictada por la Sala Especial prevista por el art. 61 LOPJ del Tribunal Supremo, el 5 de octubre de 2003, en el recurso número 6/2003, y el Acuerdo de la Junta Electoral de Zona de Pamplona de 29 de septiembre de 2003 por el que se deniega la proclamación de candidaturas, exclusivamente en lo que referido a la candidatura $\mathrm{n}^{\circ}$ 11, de «Herri Taldea», retrotrayendo las actuaciones al momento anterior a la adopción de dicho Acuerdo para que se proceda a proclamar y publicar la candidatura presentada por la recurrente en los términos en los que se presentó.

(Sentencia del Tribunal Constitucional n. ${ }^{\circ}$ 176/2003 (Sala Segunda), de 10 octubre. BOE 23-10-2003. Ponente: E. Gay Montalvo).

2. Recurso de amparo electoral $n .^{\circ} 4456 / 2003$, promovido por la coalición electoral Partido Socialista Obrero Español/Esquerra Unida-Entesa, contra la Sentencia de la Sección Electoral de la Sala de lo Contencioso-Administrativo del Tribunal Superior de Justicia de la Comunidad Valenciana $n{ }^{\circ}$ 953/2003, de 1 de julio, estimatoria del recurso contencioso-electoral interpuesto contra el Acuerdo de la Junta Electoral de Zona de Sueca, de 16 de junio de 2003, por el que 
se asignó el puesto de Diputado Provincial a la coalición electoral recurrente en amparo.

Derecho fundamental a acceder en condiciones de igualdad a las funciones y cargos públicos. Principio de conservación de los actos válidamente celebrados: singular trascendencia en el derecho electoral. Vía administrativa previa del art. 108 LOREG. Sentencia que anula la asignación de diputados por entender que la coalición electoral realmente eran dos coaliciones diferentes en el municipio de Cullera al estar integrada por un partido politico diferente respecto de los que la integraban en el resto de municipios del Partido Judicial de Sueca. El TC otorga el amparo.

«La recurrente en amparo denuncia, en primer término, que el recurso contencioso-electoral se interpuso sin haber agotado la vía administrativa previa, pues, en su opinión, de conformidad con lo dispuesto en el art. 108 LOREG, antes de haberse interpuesto dicho recurso debió formularse reclamación ante la propia Junta Electoral de Zona que había dictado el Acuerdo asignándole el Diputado Provincial correspondiente al partido judicial de Sueca y, en su caso, contra la desestimación de dicha reclamación debió de acudirse ante la Junta Electoral Central.

La coalición demandante de amparo no formuló ante el órgano judicial, pudiendo y debiendo haberlo hecho en el trámite de alegaciones a la demanda del recurso contencioso-electoral, queja alguna en relación con la falta de agotamiento de la vía administrativa previa, por lo que la cuestión planteada se suscita por vez primera en la demanda de amparo y se trae «per saltum» ante este Tribunal, incumpliendo, como ha puesto de manifiesto la representación procesal de don Eugenio P. M., el requisito de viabilidad que establece el art. 44.1 c) LOTC. Es preciso concluir, pues, que dicha queja incurre en la causa de inadmisibilidad prevista en el art. 50.1 a), en relación con el art. 44.1 c), ambos de la LOTC, esto es, en la falta de invocación en el proceso del derecho constitucional supuestamente vulnerado (STC 184/2001, de 17 de septiembre, F. 2, por todas).

En todo caso ha de señalarse, a mayor abundamiento, que la vía administrativa previa del art. 108 LOREG está prevista en relación con los actos de escrutinio de las mesas y de las Juntas Electorales, y no cabe extenderla, sin más, a falta de una expresa previsión legal, a las operaciones relativas a la asignación y proclamación de Diputados provinciales que regulan los arts. 205 y ss. LOREG, preceptos en los que no se dispone ninguna vía administrativa previa a la interposición del recurso con- 
tencioso-electoral contra los Acuerdos de las Juntas Electorales de Zona de proclamación de Diputados provinciales electos.

Es cierto, cómo la coalición recurrente en amparo denunció ante el órgano judicial «a quo», queja que, sin embargo, no reitera en la demanda de amparo, que el recurso contencioso-electoral está únicamente previsto, en lo que ahora interesa, contra la proclamación de electos (art. 109 LOREG), y que en este caso se interpuso frente a un acto o acuerdo previo a dicha proclamación, cual fue el de la asignación por la Junta Electoral de Zona del único Diputado provincial del partido judicial de Sueca a la coalición electoral Partido Socialista Obrero Español/Esquerra UnidaEntesa. Esto es, el recurso contencioso-electoral fue promovido antes de que por los concejales electos en las listas de la coalición recurrente en amparo se procediera a la elección del Diputado provincial y de los suplentes, y de que la Junta Electoral de Zona los proclamara Diputados electos, determinando su admisión a trámite la suspensión por la Junta Electoral de Zona del procedimiento electoral en curso. No obstante la denunciada irregularidad procedimental, aun en el supuesto de que pudiera constituir una infracción de la legislación electoral, de ningún modo ha vulnerado o mermado derecho fundamental alguno de la coalición electoral recurrente, ni, como se ha señalado, nada alega ésta al respecto en la demanda de amparo, debiendo resaltarse que en este caso, dadas las circunstancias concurrentes en el mismo, el Acuerdo de la Junta Electoral de Zona de asignación del único Diputado provincial que corresponde al partido judicial de Sueca incidía de forma sustancial en la posterior elección y proclamación del Diputado Provincial (STC 31/1993, de 26 de enero, F. 1), pues del éxito o fracaso del recurso contencioso-electoral dependía la asignación de dicho Diputado a una u otra fuerza política». (Vid. f.j. 2).

«En relación con la invocación que en la demanda de amparo se hace del principio de conservación de los actos válidamente celebrados y su posible afectación por la Sentencia recurrida, ha de señalarse, como ha tenido ocasión de declarar este Tribunal, que dicho principio, que puede entenderse recogido en el brocardo clásico «utile per inutile non vitiatur», y que en nuestro Ordenamiento está reconocido, entre otros preceptos, en el art. 242 LOPJ, tiende a restringir la sanción anulatoria, no extendiéndola más allá de sus confines estrictos en cada caso, evitando que una indebida ampliación de sus efectos dañe derechos de terceros, habiendo destacado su especial trascendencia en el Derecho público, dado el interés general presente en el mismo (ATC 120/1983, de 21 de marzo) y su indudable trascendencia en el Derecho electoral (SSTC 167/1987, de 28 de octubre, 167], F. 4; 24/1990, de 15 de febrero, F. 6; 25/1990, de 15 de febrero, F. 6). Pues bien, en el presente supuesto el órgano judicial en la 
Sentencia impugnada se circunscribe a pronunciarse sobre si la coalición electoral Partido Socialista Obrero Español/Esquerra Unida-Entesa y la coalición electoral Partido Socialista Obrero Español/Alternativa Progresista-Entesa son una misma coalición electoral o, por el contrario, si se trata de dos coaliciones electores distintas, sin que de la conclusión a la que llega anude sanción anulatoria alguna respecto al procedimiento electoral o a alguna de sus fases, en general, y, en particular, a las actuaciones electorales de las que considera dos coaliciones electorales, preservando, por el contrario, dichas actuaciones, si bien al entender que se trata de dos coaliciones electorales distintas impide que se computen conjuntamente los votos de una y otra a los efectos de la asignación del puesto de Diputado provincial. No cabe apreciar, por tanto, en la Sentencia recurrida una quiebra del principio de conservación de los actos válidamente celebrados, con el alcance que a dicho principio ha conferido este Tribunal en el procedimiento electoral, vulneradora de algunos de los derechos fundamentales invocados en la demanda de amparo.

En este sentido ha de rechazarse igualmente la queja de indefensión que la coalición electoral demandante de amparo imputa a la Sentencia recurrida, pues en ninguna situación de ilegalidad o alegalidad se declara a una u otra coalición electoral. Consecuencia jurídica que de haberse dado sería en todo caso imputable a los representantes o dirigentes de la coalición demandante de amparo o de los partidos políticos que la integran por una actuación electoral que el órgano judicial ha considerado contraria al Ordenamiento jurídico. Por lo demás la coalición demandante de amparo en modo alguno ha visto cercenada sus posibilidades de defensa durante el proceso, pudiendo haber efectuado, como efectivamente lo hizo, cuantas alegaciones estimó pertinentes en la defensa de sus derechos e intereses.

De otra parte, y por lo que respecta a la denunciada afectación de la doctrina de los actos propios, ha de recordarse, una vez más, para desestimar también en este extremo la queja de la recurrente en amparo, que, según reiterada doctrina constitucional, ninguna conexión guarda dicha doctrina con el cuadro de derechos fundamentales y libertades públicas, quedando, por consiguiente, en cuanto cuestión de mera legalidad ordinaria, fuera del ámbito del recurso de amparo, no pudiéndose deducir de la eventual infracción de dicha doctrina «eo ipso» violación alguna de derechos fundamentales (SSTC 32/1988, de 29 de febrero, F. 3; 73/1988, de 21 de abril, F. 5; 117/1988, de 20 de junio, F. 2; 122/1988, de 22 de junio, F. 2; 127/1988, de 24 de junio, F. 2; 136/1988, de 4 de junio, F. 2; 205/2001, de 15 de octubre, F. 6; ATC 77/1993, de 1 de marzo)». (f.j. 4). 
«(...)El principio de igualdad es ciertamente un elemento esencial del derecho a acceder a los cargos de representación política, pero éste no agota ahí su contenido. Estando condicionado su ejercicio a los requisitos que señalen las Leyes, se trata de un derecho de configuración legal, en el que este Tribunal ha declarado que es obligado integrar, desde la perspectiva del derecho de sufragio pasivo, «la exigencia de que las normas electorales sean cumplidas en cuanto constituyen garantía del correcto desarrollo de la elección de modo que culmine con la proclamación de los candidatos que hayan sido preferidos por el cuerpo electoral» (STC 71/1989, de 20 de abril, F. 3). Tal aserto, sin embargo, no debe de llevar a la identificación del contenido del derecho reconocido en el art. 23.2 CEcon toda la legalidad electoral sin más, ni puede aislarse, descontextualizándolo de las consideraciones que en aquella Sentencia se hacían sobre el contenido esencial del derecho de sufragio pasivo, que no es otro que asegurar que accedan al cargo público aquellos candidatos que los electores hayan elegido como sus representantes, satisfaciéndose, por tanto, dicho derecho siempre que se mantenga la debida correlación entre la voluntad del cuerpo electoral y la proclamación de los candidatos, así como sobre la necesidad de que las irregularidades o anomalías del procedimiento electoral denunciadas afecten al resultado final de la elección para poder apreciar la existencia de una lesión real y efectiva del derecho de sufragio pasivo [«ibidem»; también, STC 185/1999, de 11 de octubre, F. 2 c)].

En tal línea argumental, este Tribunal tiene declarado que, tanto las normas que establecen los requisitos para el acceso a los cargos públicos representativos, como los actos de aplicación de esas normas pueden ser impugnados en esta sede jurisdiccional, no sólo por quiebra de la igualdad, sino por cualquier otro género de inadecuación, por no ser congruentes con su naturaleza de cargos representativos. Por lo que, al conocer de un recurso de amparo en el que se impugna una decisión judicial recaída en un proceso contencioso-electoral, su función de fiscalización no ha de circunscribirse a examinar la cuestión exclusivamente desde el ángulo de la igualdad, sino que también ha de comprender la perspectiva más amplia que exige que tanto el legislador, al establecer los requisitos cuyo cumplimiento es necesario para acceder al cargo, como el aplicador de la norma, al aplicarla, aseguren al máximo la efectividad de los derechos fundamentales que están en la base de los órganos representativos [STC 185/1999, de 11 de octubre, F. 4 c)]». (f.j. 6).

«(...)En el presente caso, como se ha señalado, la coalición electoral demandante de amparo hizo constar expresamente en el acuerdo o pacto de coalición, debidamente comunicado a la Junta Electoral competente, su 
denominación, siglas y logotipo en cinco de los municipios del partido judicial de Sueca, y los que con carácter específico utilizaría en el municipio de Cullera, empleando como denominación identificadora común en todos ellos PSOE-ENTESA, y con tales elementos identificadores recogidos en el acuerdo o pacto de coalición concurrió a las elecciones en todos los municipios que abarcaban el ámbito de la coalición, por lo que, con base en los mismos, en modo alguno cabe inferir, a partir de la voluntad explícitamente manifestada por las fuerzas políticas integrantes de la coalición en el acuerdo o pacto de su constitución, que el partido político Esquerra Unida no concurrió a las elecciones, formando parte de la coalición, en el municipio de Cullera, ni que tampoco lo hizo, formando también parte de la coalición, el partido político Alternativa Progresista de Cullera en los otros municipios del partido judicial de Sueca. Por el contrario, la lectura de aquel pacto o acuerdo, que en ningún momento fue cuestionado durante el procedimiento electoral, y que constituye el elemento determinante tanto del ámbito subjetivo como territorial de la coalición, pone de manifiesto, como señala el Ministerio Fiscal, la expresa voluntad de los partidos políticos que lo firmaron de constituir una única coalición y comparecer como tal al proceso electoral, en lo que ahora interesa, en todos los municipios del partido judicial de Sueca.

Cierto es, de acuerdo con una reiterada doctrina constitucional, que la denominación, siglas y símbolos de los instrumentos de participación política y electoral -partidos, coaliciones, federaciones, agrupaciones de electores- son un elemento fundamental de los mismos, no sólo porque sirven como elemento intrínseco de configuración, sino, y sobre todo, por constituir un medio fundamental de identificación para el ciudadano, ya que están al servicio de una identificación clara y distinta de quien presente la candidatura para que la voluntad política que los sufragios expresen se corresponda, con la mayor fidelidad posible, a la entidad real de quien, a lo largo de la campaña electoral, así los recabe (SSTC 69/1986, de 28 de mayo, F. 2; 103/1991, de 13 de mayo, F. 2). Sin embargo la doctrina constitucional reseñada en modo alguno puede empañar en este caso la conclusión alcanzada, pues nada se razona ni argumenta en la Sentencia recurrida respecto a qué denominación, siglas y logotipo específicos utilizados por la coalición electoral demandante de amparo en el municipio de Cullera, junto a la denominación identificadora común a todos los municipios PSOE-ENTESA, hayan podido inducir a confusión en este supuesto al electorado en relación con los integrantes de la entidad política que a lo largo de la campaña electoral recabó su voto.

Tampoco cabe inferir la no presencia del partido político Esquerra Unida del País Valencià en el municipio de Cullera, como sostiene en su 
escrito de alegaciones quien ha comparecido como parte demandada en este proceso constitucional, de la circunstancia de que ninguno de los candidatos incluidos en la candidatura presentada por la coalición electoral recurrente en amparo en el referido municipio se acogiese a las siglas y al logotipo de dicho partido político, pues la legislación electoral (art. 44.2 LOREG) en momento alguno establece como requisito para la constitución y presentación de candidaturas por una coalición electoral que cada partido político que la integre haya de presentar candidatos, que además utilicen sus siglas y logotipo en cada una de las circunscripciones o distritos electorales que comprendan el ámbito de la coalición.

Ha de concluirse, pues, que, tratándose, como en este caso se trata, según resulta del acuerdo o pacto de constitución, de una única coalición electoral, la Sentencia recurrida en amparo ha vulnerado el derecho a acceder en condiciones de igualdad a los cargos públicos con los requisitos que señalen las Leyes (art. 23.2 CE), al impedir a la demandante de amparo que, a los efectos de la asignación del Diputado provincial que corresponde al partido judicial de Sueca, se le computen los votos obtenidos en los seis municipios de dicho partido judicial». (Vid. f.j. 11).

Fallo: Se acuerda estimar la presente demanda de amparo y, en su virtud:

$1^{\circ}$ Declarar que se ha vulnerado el derecho de la coalición electoral demandante de amparo a acceder en condiciones de igualdad a los cargos públicos con los requisitos que señalen las Leyes (art. 23.2 CE).

$2^{\circ}$ Restablecerla en su derecho, y, a tal fin, declarar la nulidad de la Sentencia de la Sección Electoral de la Sala de lo Contencioso-Administrativo del Tribunal Superior de Justicia de la Comunidad Valenciana ${ }^{\circ}{ }^{\circ}$ $953 / 2003$, de 1 de julio, recaída en el recurso contencioso-electoral $\mathrm{n}^{\circ}$ 1479-2003 contra el Acuerdo de la Junta Electoral de Zona de Sueca, de 16 de junio de 2003, por el que se asignó el puesto de Diputado provincial a la coalición electoral Partido Socialista Obrero Español/Esquerra Unida-Entesa.

(Sentencia del Tribunal Constitucional n. ${ }^{\circ}$ 154/2003 (Sala Segunda), de 17 julio. BOE 13-08-2003. Ponente: V. Conde Martín de Hijas).

3. Recursos de amparo interpuestos por más de 300 agrupaciones de electores de la Comunidad Autónoma del País Vasco contra las Sentencias dictadas por la Sala Especial del art. 61 LOPJ del Tribunal Supremo de 3 de mayo de 2003 en los recursos contencioso-electorales 1/2003 y 
2/2003 y que anularon la proclamación de candidaturas de dichas agrupaciones para las elecciones municipales y autonómicas de 25 de mayo de 2003. Agrupaciones de electores que supuestamente vendrían a continuar o suceder la actividad de un partido político declarado judicialmente ilegal o disuelto, o suspendido. Se otorga parcialmente el amparo solicitado.

«El examen de las candidaturas cuya proclamación ha rechazado el Tribunal Supremo arroja como primer resultado la concurrencia en todos los casos de un evidente denominador común, a saber, la presencia de personas que han pertenecido a los partidos disueltos o han concurrido en sus listas a comicios precedentes. En buen número de supuestos, además, a ese dato se añade el de la localización de esas personas en los primeros puestos de la correspondiente lista electoral, así como el hecho de que en el pasado inmediato muchos candidatos han sido concejales. Ya en menor medida, algunas agrupaciones incluyen candidatos en prisión por pertenencia a banda armada. Junto a estas referencias de orden personal, la Sala sentenciadora ha considerado relevante la solución de continuidad orgánico-funcional representada por la utilización de las siglas « $\mathrm{AuB}$ » en la denominación de algunas candidaturas, circunstancia ésta que por sí sola sería ya suficiente para acreditar de manera incuestionable la conexión con los partidos disueltos, pues la plataforma así denominada se ha constituido, precisamente y según se ha acreditado, a los solos fines de propiciar la continuidad de esos partidos a través de las agrupaciones electorales articuladas a su alrededor. A partir de todas estas referencias y circunstancias, amalgamadas en un conjunto del que resulta, por precipitación, un sólido material probatorio, la Sala ha concluido que las agrupaciones ahora recurrentes están integradas en la trama defraudatoria cuya existencia, según se ha dicho, se ha tenido razonablemente por probada.

La conexión de todas las agrupaciones en el entramado con el que, según se ha constatado razonable y motivadamente, se quiere dar continuidad fraudulentamente a los partidos disueltos sólo puede acreditarse mediante un juicio de inferencias a partir de datos probados y de significación indiscutible que evidencien la conexión de las agrupaciones con el partido político disuelto. Así, la presencia de candidatos que han tenido relación con los partidos disueltos en una proporción superior o cercana al 50 por 100 , que se sitúan, además, predominantemente, en puestos relevantes de su respectiva candidatura, que en la actualidad ocupan cargos electivos obtenidos en listas presentadas por los partidos ilegalizados, que desempeñan un papel protagonista o de relevancia en la concertación de la trama defraudatoria articulada alrededor de plataformas constituidas con el designio de burlar los efectos de la Sentencia del Tribunal Supre- 
mo de 27 de marzo de 2003, o que pretenden, en fin, concurrir a las próximas elecciones bajo denominaciones que incluyen una referencia explícita a la plataforma $\mathrm{AuB}$, sólo puede interpretarse, razonablemente, una vez acreditada la existencia de aquella trama, como la expresión de un concierto de voluntades con el que se da cuerpo a los designios inspirados por la estrategia defraudatoria que quiere propiciarse. En estas circunstancias se encuentra la práctica totalidad de las agrupaciones recurrentes, que en el mejor de los casos reducen aquella proporción al 20 por 100, siempre acompañada de la presencia de esos candidatos en puestos relevantes y de la concurrencia de quienes ya son electos.

La Sala del art. 61 LOPJ ha entendido que del cúmulo de circunstancias acreditadas debía desprenderse la conclusión de que las agrupaciones recurrentes, lejos de responder al designio de espontaneidad característico de esa institución, son fruto del entramado organizativo constituido con el propósito de continuar o suceder la actividad de los partidos políticos judicialmente disueltos. En esta sede de amparo sólo nos cabe revisar esa apreciación en aquellos supuestos en los que, desde los propios criterios interpretativos asumidos por el Tribunal Supremo, la convicción alcanzada pugne con un derecho constitucionalmente relevante; en el caso, el derecho de sufragio pasivo. En definitiva, estando en juego la efectividad del ejercicio de un derecho fundamental, este Tribunal Constitucional, ponderando los derechos individuales en presencia y el interés general del ordenamiento en la sujeción de los procedimientos electorales al principio de legalidad, debe verificar aquella revisión con arreglo a un canon decisorio cuyo contenido ha de depender de la apreciación conjunta de una pluralidad de magnitudes y referencias, entre las que ha de contarse, además del porcentaje de candidatos vinculados específicamente a las formaciones ilegalizadas, la naturaleza y relevancia de esa vinculación, la importancia del papel desempeñado por cada uno de aquellos candidatos en las distintas candidaturas analizadas -uno de cuyos datos expresivos es, por lo general, su posición en la lista electoral-, el desempeño de cargos públicos relacionados con los partidos disueltos o la existencia de condenas penales. La conjugación de todos estos factores ha de ser de tal naturaleza que permita inferir, de modo razonable y no arbitrario, que la agrupación electoral excluida del proceso electoral ha actuado, de hecho, como continuadora de la actividad de los partidos ilegalizados.

Ponderadas en su conjunto todas estas circunstancias, la eventualidad de que se sacrifique el ejercicio de un derecho fundamental exige aquí que se extreme el rigor del enjuiciamiento y se subordine a toda otra consideración la garantía de ese ejercicio. Así, en primer lugar, es evidente que la obligada ponderación de los derechos e intereses en conflicto ha de llevar 
a la estimación de los recursos interpuestos por aquellas agrupaciones electorales cuya integración en la trama defraudatoria se acredita con el dato de la inclusión entre los componentes de las candidaturas por ellos presentadas de una sola persona relacionada organizativamente con los partidos disueltos, de manera que en algún supuesto la relación entre el total de candidatos y la persona vinculada con aquéllos es de 20 a 1 . La vinculación con el partido disuelto es, desde luego, un dato relevante, pero sólo si concurre de manera significativa en una agrupación o si, ya en términos cualitativos, se predica de quien probadamente ha desempeñado en el partido disuelto una posición especialmente relevante o hace lo propio en la plataforma arbitrada para la orquestación de todas las agrupaciones integradas en la estrategia defraudatoria que el Tribunal Supremo ha declarado probada. En otro caso, la sola presencia de un candidato afectado por esa vinculación, ni supone indicio bastante, a falta de otras circunstancias, para apreciar la concertación defraudatoria, ni puede perjudicar el derecho de quienes con él participan de consuno en un proceso electoral. Tal perjuicio sólo puede justificarse, en términos constitucionales que pasan por un ponderado juicio de proporcionalidad entre el fin perseguido y el derecho sacrificado como medio, si se acredita una voluntad cierta de desnaturalización de las agrupaciones electorales mediante su conversión en elementos constitutivos de un partido «de facto» que dé continuidad a otro disuelto. Y tal extremo no puede desprenderse, razonablemente, del solo dato de la presencia de un candidato relacionado con el partido ilegalizado. Evidentemente, también este tipo de agrupaciones pudieran estar concertadas en la estrategia de continuidad probada por la Sala, como también pueden estarlo otras que ni siquiera ofrezcan ese mínimo indicio. Sin embargo, lo determinante es que esa concertación quede razonablemente probada, lo que no puede ser el caso sin la presencia de algún elemento añadido.

No obstante, el anterior no puede ser el único criterio a utilizar. También, y por razón del mismo orden de consideraciones, procede también otorgar el amparo a toda aquellas candidaturas que, aunque presenten un número superior de candidatos, ofrecen otras características diferenciales. Se trata de las que, a diferencia de la práctica totalidad de las que han visto anulada su proclamación, se mueven en parámetros que, conforme a los anteriores criterios, permiten albergar dudas razonables acerca de su condición de elementos continuadores de los partidos ilegalizados. En efecto, no puede considerarse acreditada la conexión fraudulenta con otras agrupaciones alrededor de la plataforma $\mathrm{AuB}$ en aquellos supuestos en los que no concurren acumuladamente una serie de factores como son, entre otros, un porcentaje significativo de candidatos vinculados con los partidos disueltos, un puesto relevante en la candidatura, la participación y eventual elección en anterio- 
res comicios en las listas de aquéllos, la ocupación de cargos institucionales en representación de los partidos ilegalizados, la posición ocupada en la estructura de éstos o de la propia plataforma $\mathrm{AuB}$ o, finalmente, la eventual implicación en la trama defraudatoria». (vid. f.j. 29)

Fallo: Se acuerda

$1^{\circ}$ Otorgar el amparo interesado por las agrupaciones electorales agrupación Electoral Mendi (AEN, recursos de amparo núms. 2667/2003 y 2796/2003), Alegikotalde Ezkertiar Abertzalea (Atea)-Alegia (recursos de amparo núms. 2697/2003 y 2698/2003), Anueko Indarra (AI, recursos de amparo núms. 2613/2003 y 2777/2003), Bagoaz (B)-Zestoa (recursos de amparo núms. 2770/2003 y 2782/2003), Belauntzako Sustraiak (BS)Belauntza (recursos de amparo núms. 2759/2003 y 2762/2003), Berriozar Baietz (BB, recursos de amparo núms. 2807/2003 y 2808/2003), Branka (B)-Hondarribia (recursos de amparo núms. 2800/2003 y 2801/2003), Erreil Bizirik (EB)-Errezil (recursos de amparo núms. 2627/2003 y 2755/2003), Herriarengatik (recursos de amparo núms. 2844/2003 y 2845/2003), Irun Herria (recursos de amparo núms. 2763/2003 y 2877/2003), Izustarri (I, recursos de amparo núms. 2702/2003 y 2706/2003), Maeztuko Aukera Candidatura Independiente (recurso de amparo n. ${ }^{\circ}$ 2603/2003), Mugarra Bingunea (MB; recursos de amparo núms. 2699/2003 y 2709/2003), Tafalla Berria (T)-Tafalla (recurso de amparo n. ${ }^{\circ}$ 2618/2003), Urdiaindarrak (U, recursos de amparo núms. 2670/2003 y 2671/2003), Zornotxa Eginez (ZE, recursos de amparo núms. 2699/2003 y 2709/2003) y, en consecuencia:

a) Reconocer su derecho a la participación política en los asuntos públicos, directamente o por medio de representantes (art. 23.1 CE);

b) Restablecerlas en su derecho y, a tal fin, anular, estrictamente en lo que a ellas se refiere, las Sentencias de la Sala Especial del art. 61 de 3 de mayo de 2003, resolutorias de los recursos núms. 1/2003 y 2/2003.

$2^{\circ}$ Desestimar las restantes demandas de amparo electoral.

(Sentencia del Tribunal Constitucional n. ${ }^{\circ}$ 85/2003 (Sala Primera), de 8 mayo. BOE 17-05-2003. Ponente: J. Rodríguez-Zapata Pérez y R. GarcíaCalvo y Montiel).

4. Recurso de amparo electoral $n .^{\circ} 2560 / 2003$, promovido por el partido Izquierda Unida contra la Sentencia $n .^{\circ} 178 / 2003$, de 30 de abril, dictada por el Juzgado de lo Contencioso-Administrativo $n .^{\circ} 2$, de los de 
Córdoba, que desestima el recurso interpuesto por el representante provincial de Córdoba de Izquierda Unida contra el Acuerdo de la Junta Electoral de Zona de Peñarroya-Pueblonuevo publicado el 29 de abril de 2003, en que no se proclaman las candidaturas presentadas por el solicitante de amparo en el municipio de Belalcázar por Izquierda Unida. Los Verdes-Convocatoria por Andalucía. Candidaturas presentadas por error ante el registro municipal, en vez de ante la Junta electoral de zona. Falta de diligencia del partido interviniente que debe de velar por la correcta presentación de su candidatura. El TC deniega el amparo.

«La lesión del derecho fundamental que da origen a este amparo electoral sería imputable al acuerdo originario de la Junta Electoral de Zona que se impugna. Y ello en la medida en que, al proclamar las candidaturas electorales que se presentan para las elecciones locales 2003 en el municipio cordobés de Belalcázar, omite cualquier referencia a la promovida por Izquierda Unida-Los Verdes-Convocatoria por Andalucía, cuya presentación, pura y simplemente, desconoce. A raíz del recurso-reclamación instado por el partido recurrente ante la Junta Electoral de Zona de Peñarroya-Pueblonuevo, en la que protesta haber presentado la candidatura en plazo conforme al llamado convenio de ventanilla única celebrado en ejecución del artículo 38.4 b) de la Ley 30/1992, de 26 de noviembre, de régimen jurídico de las Administraciones públicas y del procedimiento administrativo común (LRJ-PAC), se pronuncia la Administración electoral acordando la inadmisión del mismo porque el registro de una entidad local no es el lugar idóneo para la presentación de una candidatura, entendiendo que la candidatura presentada, finalmente, en la sede idónea lo fue una vez que había expirado el plazo legalmente previsto para ello, por lo que debe considerarse, a efectos jurídicos, como inexistente.

El partido político que se queja en amparo cuestiona, sin embargo, la supuesta incorrección formal que la Administración electoral ha apreciado en la formalización de su candidatura. A su entender, la presentación se hizo en plazo ante el Registro del Ayuntamiento de Peñarroya-Pueblonuevo, que debió transmitirla a la Junta Electoral correspondiente facilitando así el ejercicio efectivo de los derechos fundamentales (como exige el art. 9.2 CE), porque esta actuación se encuadra en el convenio suscrito entre la citada corporación local y la Administración General del Estado el 26 de junio de 1996. De tal forma que la vulneración del derecho fundamental contenido en el art. 23.2 CE traería causa, en definitiva, también de una supuesta inacción de la Administración local». (Vid. f.j. 3).

«(...)En este sentido, se declaró en la STC 197/1988, de 24 de octubre, que, precisamente por la misión trascendental que la Ley Orgánica del 
régimen electoral general encomienda a las Juntas Electorales, de asegurar la transparencia y objetividad del proceso electoral, así como del principio de igualdad, estos órganos de la Administración electoral presentan, en su composición y funciones, notables peculiaridades que las apartan del régimen general de las Administraciones públicas; eso explica que la composición de las referidas Juntas esté -desde la Junta Electoral Central hasta las de Zona- judicializada en forma muy decisiva siendo, además, todos sus miembros inamovibles durante los períodos para los que son elegidos, sin guardar, obviamente, relación alguna de dependencia con la Administración (F. 2). Esta peculiar naturaleza de la Administración electoral, que por ello no puede encuadrarse en modo alguno en el concepto genérico de Administraciones públicas, se corrobora claramente en la Ley 29/1998, de 13 de julio, reguladora de la jurisdicción Contencioso-Administrativa. El apartado 2 del artículo 1 de dicha Ley excluye meridianamente a la Administración electoral de la cláusula general de enumeración que acota el concepto de Administraciones públicas y sólo admite, en su apartado 3, que la jurisdicción del orden contencioso conozca de la actuación de la Administración electoral tras la consideración de los órganos que incluye en dicho apartado, separando, en fin, con claridad, de ellos a la Administración electoral en un apartado c) que, significativamente, se somete para el control de su actuación por la jurisdicción ContenciosoAdministrativa a «los términos previstos en la Ley Orgánica del Régimen Electoral General».

Todos estos datos nos conducen a concluir que la Administración electoral no puede ser subsumida, en el sentido que pretende el partido recurrente, entre las Administraciones públicas a las que es de aplicación el artículo 38.4 b) LRJ-PAC, lo que dificulta ya, en términos de interpretación normativa, la tesis que se sostiene de aplicabilidad del convenio suscrito entre el Ayuntamiento de Peñarroya-Pueblonuevo con la Administración General del Estado, en desarrollo del art. 38.4 b) LRJ-PAC». (Vid. f.j. 5).

«Pero es que, además, para que tal convenio fuera aplicable, como sostiene la demandante, debería aceptarse, previamente, la supletoriedad del artículo 38.4 LRJ-PAC respecto de la legislación electoral, lo que no cabe, por cuanto en dicho caso ello llevaría a poner en peligro la regularidad de todo el proceso electoral, con el consiguiente daño al interés público y a los valores democráticos anteriormente recordados.

El art. 120 LOREG dispone que en «todo lo expresamente no regulado por esta Ley en materia de procedimiento será de aplicación la Ley de Procedimiento Administrativo». Pues bien, en el presente caso la simple 
invocación de la máxima «in claris non fit interpretatio» debería limitar el examen de la cuestión concreta que se nos plantea a elucidar, sin más trámite, si el art. 45 LOREG regula expresa, clara y taxativamente tanto el lugar como el plazo de presentación de candidaturas y, en caso positivo, desechar que la Ley de procedimiento administrativo pueda ser traída a colación como derecho supletorio. Desde el ámbito de reserva de Ley orgánica que cubre la materia, y en la forma clara, expresa e inequívoca que se adopta para las normas de la máxima trascendencia constitucional cuando se trata de evitar cualquier duda hermenéutica, el art. 45 LOREG regula, atendido al tenor literal de sus palabras, tanto el lugar en que deberán ser presentadas las candidaturas («ante la Junta Electoral competente») como el momento de presentación («entre el decimoquinto y el vigésimo día posteriores a la convocatoria») por lo que, a la luz del propio art. 120 LOREG «no queda margen para la supletoriedad pretendida» (STC 80/2002, de 8 de abril, F. 3.b)».

(...) la conclusión a que antes llegábamos se refuerza en cuanto la aplicación del art. 38.4 LRJ-PAC al procedimiento electoral tendría como efecto inmediato imposibilitar el cumplimiento de los fugaces y exiguos plazos preclusivos previstos en la Ley Orgánica del régimen electoral general haciendo imposible la práctica del proceso electoral mismo, puesto que habría que reputar válida la presentación de la candidatura efectuada por cualesquiera de los medios allí previstos. Ese carácter fugaz, perentorio y preclusivo de los plazos en los procedimientos electorales ha sido destacado reiteradamente por nuestra jurisprudencia (SSTC 170/1991, de 19 de julio, 73/1995, de 12 de mayo, y 93/1999, de 27 de mayo) advirtiendo la extrema diligencia con la que deben actuar tanto la Administración electoral como las propias partes ante esta circunstancia. (Vid. f.j. 6).

«Aunque la simple confirmación de la actuación de la Administración electoral conduciría directamente a la desestimación del amparo electoral solicitado, es oportuno poner de manifiesto que, en el caso que nos ocupa, la formación política recurrente ha mostrado una clara falta de diligencia, contraria a la actuación que exige nuestra jurisprudencia (STC 67/1987, de 21 de mayo, F. 2) y que también determina la imposibilidad de alegar con éxito supuestas vulneraciones de derechos derivados del artículo 23 de la Constitución (RCL 1978, 2836). En efecto, la propia solicitante de amparo ha reconocido en forma expresa, en la demanda de amparo y en el recurso-reclamación ante la Junta Electoral de Zona, que la presentación de la candidatura litigiosa en el Registro municipal se ha debido, en realidad, a un error. Conforme a lo alegado por el Ministerio Fiscal, la ausencia de seguimiento de la candidatura muestra, en esa circunstancia, 
una clara falta de diligencia ya que la Teniente de Alcalde y representante de la solicitante de amparo pudo y debió cerciorarse del estado de la candidatura, así como si se había tramitado o no ante la Junta Electoral de Zona; sin embargo no compareció ante dicha Junta hasta dos días después de que se hubiera cerrado el plazo preclusivo de presentación, no quedando enervada esa falta de atención por el alegato de existencia de varios días festivos». (Vid. f.j. 8).

Fallo: Se desestima el recurso de amparo interpuesto por Izquierda Unida (Izquierda Unida, Los Verdes-Convocatoria por Andalucía).

(Sentencia del Tribunal Constitucional n. ${ }^{\circ} 83 / 2003$ (Sala Primera), de 5 mayo. BOE 17-05-2003. Ponente: J. Rodríguez-Zapata Pérez).

\section{JURISDICCIÓN CONTENCIOSO-ADMINISTRATIVA}

1. Recurso de amparo $n^{\circ}$ 3715-2000, promovido por la entidad mercantil Ferrovial, S.A.contra la Sentencia de la Sección Segunda de la Sala de lo Contencioso-Administrativo del Tribunal Supremo con fecha 22 de abril de 2000 , por la que se desestima el recurso de casación interpuesto contra la Sentencia de la Sala de lo Contencioso-Administrativo del Tribunal Superior de Justicia de Extremadura de fecha 10 de junio de 1995, que inadmitió el recurso contencioso-administrativo interpuesto contra el requerimiento de pago de una liquidación tributaria en concepto de impuesto sobre construcciones, instalaciones y obras. Actos administrativos declarados firmes y consentidos por no haber impugnado judicialmente en plazo la desestimación presunta del recurso de reposición. Se alega vulneración del derecho fundamental a obtener la tutela efectiva de jueces y tribunales. El TC otorga el amparo.

«Con carácter previo al estudio de la cuestión que se nos plantea es necesario dar respuesta a la objeción de carácter procesal articulada por el Ayuntamiento de Mérida, relativa a la falta de invocación formal en el proceso del derecho constitucional vulnerado (art. 44.1.c LOTC), extremo que, de confirmarse, determinaría la inadmisión del recurso en este momento procesal, de acuerdo con lo establecido en el art. 50.1 a) LOTC, pues los defectos insubsanables de que pudiera estar afectado el recurso de amparo no resultan subsanados porque el recurso haya sido inicialmente admitido a trámite (entre las últimas, SSTC 15/2003, de 28 de enero, F. 2; 24/2003, de 10 de febrero, F. 2; 57/2003, de 24 de marzo, F. 
2; 69/2003, de 9 de abril, F. 2; 89/2003, de 19 de mayo, F. 2; 93/2003, de 19 de mayo, F. 2; 145/2003, de 14 de julio, F. 2; 159/2003, de 15 de septiembre, F. 4; 163/2003, de 29 de septiembre, F. 2; y 188/2003, de 27 de octubre, F. 2).

Aunque con el requisito de la invocación se pretende preservar la prioridad de los órganos judiciales en el conocimiento y restablecimiento de los derechos fundamentales, este Tribunal ha venido efectuando una interpretación flexible al reconocer que no es exigible la cita del precepto constitucional concreto que se estima vulnerado, ni tampoco la reproducción de su nomen iuris o calificación jurídica de la norma fundamental vulnerada, siendo lo realmente relevante para entenderlo cumplido el hecho de haberla planteado en términos tales que pueda identificarse como descripción de la violación de un derecho fundamental y permita, por tanto, al órgano judicial, conocida por manifestada la relevancia constitucional de la eventual lesión, pronunciarse respecto a su restablecimiento, por lo que, basta para considerar cumplido el requisito con que de las alegaciones del recurrente pueda inferirse la lesión del derecho fundamental que luego se intente invocar en el recurso de amparo (entre las últimas, SSTC 136/2002, de 3 de junio, F. 3; 133/2003, de 30 de junio, F. 2; 134/2003, de 30 de junio, F. 2; 153/2003, de 17 de julio, F. 4; y 159/2003, de 15 de septiembre, F. 3).

Pues bien, al amparo de la doctrina expuesta no cabe sino desestimar la causa de inadmisión citada, pues basta con acudir al escrito de formalización del recurso de casación de fecha 7 de agosto de 1995, primer momento en que cabía invocar la lesión del derecho a la tutela judicial efectiva por la Sentencia del Tribunal Superior de Justicia de Extremadura impugnada, para comprobar cómo se infiere con total precisión la vulneración constitucional imputada a la resolución judicial, pues la parte actora dedica enteramente su primer motivo casacional a exteriorizar aquella vulneración con cita precisa de doctrina constitucional dictada en supuestos similares (en concreto, las SSTC de 21 de enero de 1986, F. 3, y de 21 de diciembre de 1987, F. 5)» (Vid. f.j. 2).

«Una vez delimitado el canon de nuestro enjuiciamiento y antes de entrar a analizar la vulneración alegada conviene recordar sucintamente los hechos que han dado lugar al presente recurso de amparo. En este sentido, es de destacar que a la recurrente en amparo se le giró una liquidación tributaria con fecha de 18 de febrero de 1992 por el concepto de impuesto sobre construcciones, instalaciones y obras, es decir, bajo la vigencia de la Ley de procedimiento administrativo de 1958, contra la cual interpuso con fecha 21 de febrero siguiente un recurso de reposición. 
Ahora bien, soslayando la Administración su obligación legal de dar respuesta expresa al citado recurso de reposición, con fecha 29 de junio de 1993 dictó nueva Resolución requiriendo a la actora de pago por agotamiento de «la vía administrativa y la jurisdiccional al haber transcurrido los plazos legales de impugnación» (a saber, el plazo de un año previsto en el art. 58.2 de la Ley de la jurisdicción contencioso-administrativa de 1956). Requerimiento de pago que motivó que la actora interpusiera un recurso contencioso-administrativo con fecha de 31 de julio de 1993, esto es, en el plazo de los dos meses siguientes al acto impugnado, en el entendimiento de que dicho requerimiento de pago implicaba además una resolución expresa desestimatoria de su previo recurso de reposición. Sin embargo, primero, la Sala de lo Contencioso-Administrativo del Tribunal Superior de Justicia de Extremadura y, luego, la Sala Tercera del Tribunal Supremo, declararon la extemporaneidad del citado recurso jurisdiccional al haber devenido la liquidación impugnada firme por consentida, al no haber sido cuestionada la desestimación presunta por silencio negativo del recurso de reposición presentado, en el plazo del año siguiente al día en que fue interpuesto (conforme estipulaba el citado art. 58.2 LJCA/1956).

Si bien es cierto que la previsión del art. 58.2 LJCA/1956 puesta en relación con la del art. $94 \mathrm{LPA} / 1958$ puede dar lugar, desde el plano de la estricta legalidad, a diferentes y variadas interpretaciones, también lo es que los órganos judiciales, asumiendo como correcta la práctica del Ayuntamiento demandado de comunicar al interesado en el primer acto del procedimiento de gestión tributaria toda la sucesión de recursos que durante el mismo pueden tener cabida, han ido a elegir la interpretación de la normativa aplicable menos respetuosa para la efectividad del derecho fundamental en juego, sin tener en cuenta ninguno de ellos que existe, en todo caso, la obligación legal para la Administración de resolver expresamente las peticiones o recursos de los ciudadanos y, en consecuencia, el derecho de éstos a recibir una respuesta expresa a sus peticiones y recursos. Pues bien, en situaciones como la que ahora se somete a nuestra consideración ya hemos tenido la oportunidad de apuntar que cuando «existe una notificación de un acto de ejecución contra el que el interesado ha interpuesto los recursos pertinentes en el plazo establecido por la Ley», hay que entender que este acto expreso de ejecución «implica al mismo tiempo una reiteración del acto resolutorio del que trae causa, que no puede entenderse consentido y, en consecuencia, reabre los plazos legales de impugnación también de dicho acto resolutorio» ( SSTC 204/1987, de 21 de diciembre, F. 5; y 188/2003, de 27 de octubre, F. 5), lo que implica que el requerimiento administrativo de pago efectuado por el Ayuntamiento demandado habilitaría a la hoy demandante de amparo no sólo a impugnar a aquél por los vicios que puedan serle imputables, 
sino también la liquidación de la que trae causa, tanto por motivos formales como materiales. En efecto, conforme a nuestra doctrina constitucional recientemente aplicada en la STC 188/2003, de 27 de octubre en los casos en los que la Administración, soslayando su deber legal de resolver de forma expresa el recurso presentado por un obligado tributario, dicta actos dirigidos a la recaudación de la deuda impugnada, bien mediante la emisión y notificación de la correspondiente providencia de apremio (como sucedió en el supuesto analizado en las SSTC 204/1987 y 188/2003), bien mediante el requerimiento de pago de la deuda impugnada (como ocurre en el presente caso), debe entenderse que el nuevo acto expreso de recaudación implica, además, una desestimación del recurso administrativo previamente interpuesto, pudiendo accionar el obligado tributario, en consecuencia, no sólo contra este nuevo acto de gestión tributaria, sino también contra aquél, del que trae causa.

Llama la atención, sin embargo, que ante el incumplimiento por parte de la corporación local demandada de su obligación legal de resolver expresamente el recurso interpuesto y ante su cuidada diligencia para declarar la firmeza de una liquidación, que en modo alguno fue consentida por la parte actora, los órganos judiciales hayan adoptado como se ha dicho de entre las varias interpretaciones posibles, la menos favorable a la efectividad del derecho fundamental en juego, esto es, aquella que prima la inactividad administrativa convirtiendo lo que conforme a la legalidad vigente era una obligación para la Administración la de resolver expresamente (art. 94.3 LPA/1958) en una opción, y en una obligación del ciudadano lo que conforme a la misma legalidad era un derecho someter el conocimiento de la cuestión controvertida a los Tribunales sin necesidad de esperar a una resolución expresa una vez superado un determinado período de inactividad administrativa (art. 94.2 LPA/1958)» (Vid. f.j. 4).

«Sobre el tema que nos ocupa hemos declarado, en reiteradas ocasiones, que la Administración no puede verse beneficiada por el incumplimiento de su obligación de resolver expresamente en plazo solicitudes de los ciudadanos, pues este deber entronca con la cláusula del Estado de Derecho (art. 1.1 CE), así como con los valores que proclaman los arts. 24.1, 103.1 y 106.1 CE (por todas, SSTC 6/1986, de 21 de enero, F. 3; 204/1987, de 21 de diciembre, F. 4; 180/1991, de 23 de septiembre, F. 1; 86/1998, de 21 de abril, FF. 5 y 6; 71/2001, de 26 de marzo, F. 4; y 188/2003, de 27 de octubre, F. 6). Por este motivo, hemos dicho también que el silencio administrativo de carácter negativo se configura como «una ficción legal que responde a la finalidad de que el administrado pueda, previos los recursos pertinentes, llegar a la vía judicial superando los efectos de inactividad de la Administración», de manera que, en estos 
casos, no puede calificarse de razonable aquella interpretación de los preceptos legales «que prima la inactividad de la Administración, colocándola en mejor situación que si hubiera cumplido su deber de resolver» [SSTC 6/1986, de 21 de enero, F. 3 c); 204/1987, de 21 de diciembre, F. 4; 180/1991, de 23 de septiembre, F. 1; 294/1994, de 7 de noviembre, F. 4; 3/2001, de 15 de enero, F. 7; y 179/2003, de 13 de octubre, F. 4].

Así, con base en la anterior doctrina hemos concluido en la reciente STC 188/2003, anteriormente citada, que «[s]i el silencio negativo es una institución creada para evitar los efectos paralizantes de la inactividad administrativa, es evidente que ante una resolución presunta de esta naturaleza el ciudadano no puede estar obligado a recurrir, siempre y en todo caso, so pretexto de convertir su inactividad en consentimiento con el acto presunto, exigiéndosele un deber de diligencia que no le es exigido a la Administración. Deducir de ese comportamiento pasivo que no olvidemos, viene derivado de la propia actitud de la Administración un consentimiento con el contenido de un acto administrativo que fue impugnado en tiempo y forma, supone una interpretación absolutamente irrazonable desde el punto de vista del derecho de acceso a la jurisdicción, como contenido esencial del derecho a la tutela judicial efectiva previsto en el art. 24.1 CE, pues no debemos descuidar que la Ley no obliga al ciudadano a recurrir un acto presunto y sí a la Administración a resolver, de forma expresa, el recurso presentado» (F. 6).

En consecuencia, habiendo optado los órganos judiciales, de entre las varias opciones interpretativas que la normativa aplicable admitía, por la menos favorable al ejercicio de la acción, esto es, por la única que cerraba de forma irrazonable y desproporcionada el acceso a la jurisdicción contencioso-administrativa, en orden a la obtención de una resolución sobre el fondo de la pretensión sometida a la consideración del órgano judicial, no cabe sino estimar el presente recurso de amparo por lesión del derecho a la tutela judicial efectiva de la entidad recurrente en amparo, pues el incumplimiento por parte de la corporación municipal demandada de su obligación legal de resolver de forma expresa el recurso de reposición interpuesto (arts. 94.3 LPA/1958 y 42 LPC/1992), de un lado, y de la obligación de comunicar precisamente por esa falta de respuesta administrativa la necesaria instrucción de recursos (arts. 79.2 LPA/1958 y 58.2 LPC/1992), de otro lado, «ha supuesto que la Administración se beneficiara de su propia irregularidad», por lo que, como este Tribunal ha manifestado reiteradamente, «no puede calificarse de razonable una interpretación que prime los defectos en la actuación de la Administración, colocándola en mejor situación que si hubiera cumplido su deber de notificar con todos los requisitos legales» (por todas, STC 179/2003, de 13 de octubre. 
Y no desdice la anterior conclusión el hecho de que la Administración demandada hubiese tenido la cautela de incluir en la liquidación impugnada no sólo los recursos pertinentes contra la propia liquidación recurso de reposición sino incluso también contra su eventual desestimación presunta recurso contencioso-administrativo, pues la citada instrucción de recursos de un acto administrativo no excusaba a la Administración de su obligación legal de resolver el recurso interpuesto, comunicando al interesado «la indicación de si es o no definitivo en la vía administrativa y, en su caso, la expresión de los recursos que contra el mismo procedan, órgano ante el que hubieran de presentarse y plazo para interponerlos» (art. 79.2 LPA/1958, hoy 58.2 de la Ley 30/1992). Es absolutamente inaceptable que una Administración pública que debe actuar «con sometimiento pleno a la ley y al Derecho» (art. 103.1 CE), desatienda, primero, el cumplimiento de sus obligaciones para con los ciudadanos y, sin embargo, manifieste luego un extremado celo en la exigencia de las de éstos, pues ninguna pretendida eficacia administrativa puede justificar el desconocimiento de uno de los valores superiores de nuestro ordenamiento jurídico: el valor justicia (art. 1.1 CE). Por este motivo, no es posible entender que la resolución desestimatoria presunta de un recurso de reposición, por silencio administrativo de carácter negativo, reúne, en modo alguno, los requisitos formales de que se debe revestir todo acto administrativo, por el simple hecho de que el acto impugnado sobre el que pende la inactividad administrativa incluyó una detallada instrucción de recursos, presentes y futuros» (Vid. f.j. 5)».

«Dicho lo que antecede, procede aún hacer una última precisión, al igual que hicimos en la STC 188/2003, de 27 de octubre, ya que, aun cuando las resoluciones judiciales impugnadas confirman el carácter firme y consentido de la liquidación girada por el Ayuntamiento de Mérida lo hacen «mediante una interpretación razonada de la normativa aplicable que no puede calificarse en modo alguno de arbitraria». Ahora bien, dado que «el canon de constitucionalidad aplicable al presente caso no es de la arbitrariedad, propio del control de las resoluciones judiciales obstativas del acceso al recurso, sino el de la proporcionalidad, que margina aquellas interpretaciones que por su rigorismo, formalismo excesivo o desproporción se conviertan en un obstáculo injustificado del derecho a que un órgano judicial resuelva sobre el fondo de la cuestión a él someti$\mathrm{da}$, debemos concluir que la exégesis que aquella incorpora a su fundamentación ha desconocido la obligada observancia del principio pro actione en el acceso a la jurisdicción, «así como las exigencias que, con carácter general, se derivan del art. 24.1 CE en relación con el orden de lo contencioso-administrativo, que ya no puede ser concebido como un cauce jurisdiccional para la protección de la sola legalidad objetiva $\mathrm{o}$, si se pre- 
fiere, como un proceso al acto, sino, fundamentalmente, como una vía jurisdiccional para la efectiva tutela de los derechos e intereses legítimos de la Administración y de los administrados» ( STC 86/1998, de 21 de abril, F. 5)» (F. 7).

Y ello porque, como ya hemos tenido oportunidad de afirmar, «la omisión de un pronunciamiento sobre el fondo, imputable a la Sentencia objeto de esta queja, desvirtúa la finalidad de la institución del silencio administrativo, por cuanto transforma en una posición procesal de ventaja lo que es, en su origen, el incumplimiento de un deber de la Administración, como el de dar respuesta expresa a las solicitudes de los ciudadanos (art. 94.3 de la aplicable LPA, y art. 42.1 de la vigente Ley 30/1992), permitiendo de tal modo que, pese a la persistente negativa o resistencia a tal deber por parte del ente público, éste quede inmune al control jurisdiccional plenario que viene exigido por el art. 106.1 de la Constitución. Se produce, así, la denunciada lesión del derecho del demandante a la tutela judicial efectiva sin indefensión proclamado por el art. 24.1 de la Norma suprema, en su más primaria o genuina manifestación, cual es la del acceso a la jurisdicción, señaladamente para articular la defensa del ciudadano frente a los poderes públicos ( STC 48/1998, F. 3.b), lo que conduce derechamente a la estimación del amparo» ( SSTC 86/1998, de 21 de abril, F. 7; y 188/2003, de 27 de octubre, F. 7)» (Vid. f.j. 6).

Fallo: Se acuerda estimar la presente demanda de amparo promovida por la entidad Ferrovial, S.A. y, en su virtud:

$1^{\circ}$ Reconocer el derecho de la recurrente en amparo a la tutela judicial efectiva (art. 24.1 CE).

$2^{\circ}$ Declarar la nulidad tanto de la Sentencia de la Sección Segunda de la Sala de lo Contencioso-Administrativo del Tribunal Supremo con fecha de 22 de abril de 2000, recaída en el recurso de casación n. ${ }^{\circ}$ 6001/95, como de la Sentencia del Tribunal Superior de Justicia de Extremadura de fecha de 10 de junio de 1995, recaída en el recurso contencioso-administrativo . $^{\circ} 855 / 93$.

$3^{\circ}$ Retrotraer las actuaciones al momento procesal inmediatamente anterior al de la referida Sentencia de la Sala de lo Contencioso-Administrativo del Tribunal Superior de Justicia de Extremadura a fin de que el órgano judicial se pronuncie con respeto al contenido del derecho fundamental vulnerado. 
(Sentencia del Tribunal Constitucional n. ${ }^{\circ}$ 220/2003 (Sala Primera), de 15 diciembre. BOE 20-1-2004. Ponente: R. García-Calvo y Montiel).

2. Recurso de amparo $n .^{\circ} 138 / 1998$, interpuesto por el Ayuntamiento de Arrúbal (La Rioja), contra la Sentencia dictada por la Sala de lo Civil del Tribunal Supremo el 26 de noviembre de 1997 en el recurso de casación $n .^{\circ}$ 2628/1993, que declara no haber lugar al recurso de casación interpuesto por la representación procesal de don Tomás V. V. y otros contra la Sentencia dictada por la Audiencia Provincial de Logroño el 21 de junio de 1993, en autos de juicio declarativo ordinario de menor cuantía $n .{ }^{\circ} 314 / 1986$ procedente del Juzgado de Primera Instancia $n .^{\circ} 2$ de Logroño. Control de legitimación. Ayuntamiento que no es llamado al proceso ni admitida su personación. El TC deniega el amparo.

«(...) Este Tribunal ha declarado insistentemente que el contenido primario del derecho fundamental a obtener la tutela judicial efectiva consagrado en el art. 24.1 CE es el acceso a la jurisdicción, que se concreta en el derecho a ser parte en un proceso para promover la actividad jurisdiccional que conduzca a la obtención de una resolución judicial sobre las pretensiones deducidas (SSTC 220/1993, de 30 de junio, F. 3, y 124/2002, de 20 de mayo, F. 3, por todas). Sin embargo, en cuanto que derecho de índole prestacional, viene conformado por las normas legales que determinan su alcance y contenido. Por ello la interpretación y el control de los presupuestos procesales que condicionan la válida constitución de proceso y la correcta formación de la relación jurídica procesal son funciones que no trascienden, en principio, del ámbito de la legalidad ordinaria y que corresponde ejercitar a los órganos judiciales conforme a lo prevenido en el art. 117.3 CE. No corresponde, por tanto, a este Tribunal Constitucional revisar la interpretación de la legalidad hecha por los órganos judiciales, salvo en casos extremos en los que «la decisión de inadmisión elimine y obstaculice injustificadamente el derecho a que un órgano judicial conozca y resuelva la pretensión formulada», empleando una interpretación rigorista, excesivamente formalista o desproporcionada en relación con los fines que se preserva y los intereses que se sacrifican (por todas, STC 59/2003, de 24 de marzo, FF. 1 y 5), o que por su arbitrariedad, error de hecho o su manifiesta falta de razonabilidad pueda lesionar el contenido medular del referido derecho constitucional a la tutela judicial (STC 124/2002, de 20 de mayo, F. 3, y la amplia jurisprudencia allí citada). En este contexto doctrinal, hemos precisado que no es cometido de este Tribunal «entrar a considerar con carácter general quiénes deben estimarse legitimados para ser parte o personarse en un determinado proceso», cuestión que incumbe resolver de ordinario a los órganos judiciales (STC 124/2002, que reproduce la doctrina recogida por la STC 
301/2000, de 11 de diciembre, F. 2); y más directamente en relación con la queja ahora formulada, hemos afirmado que no le compete a este Tribunal pronunciarse sobre la existencia o no de litisconsorcio pasivo necesario, al ser una cuestión que tiene que ser valorada y enjuiciada con arreglo a la legislación ordinaria, limitándose la competencia de este Tribunal a constatar que su admisión o desestimación ha sido debidamente razonada y fundada (SSTC 77/1986, de 12 de junio, F. 1; 335/1994, de 19 de diciembre, FF. 4 y 5; 165/1999, de 27 de septiembre, F. 3). (Vid. f.j. 4).

«(...)La resolución del presente recurso exige finalmente contrastar si, de un lado, la entidad recurrente obtuvo respuesta motivada respecto a su intento de comparecencia, y, de otro lado, si la falta de llamamiento al proceso de la corporación municipal demandante de amparo por el órgano judicial provocó su pretendida indefensión material.

a) Respecto de la primera cuestión planteada, basta el examen de las actuaciones seguidas en el procedimiento civil de referencia para comprobar que la comparecencia intentada por la entidad recurrente tras dictarse en segunda instancia la Sentencia de 21 de junio de 1993 por la Audiencia Provincial de Logroño con el fin de recurrir en casación la misma, fue objeto de resolución de la propia Audiencia mediante providencia de 4 de octubre de 1993 en la que el órgano judicial excusaba pronunciarse sobre lo solicitado al estimar «perdida su jurisdicción tras dictarse Sentencia y ser recurrida en casación la misma por tres de las partes comparecidas en el proceso». Con posterioridad a este pronunciamiento, es la propia Sala de lo Civil del Tribunal Supremo la que aborda este asunto de manera explícita a requerimiento de las dos partes recurrentes en casación (no así de entidad demandante de amparo, según se expuso con anterioridad) que defienden la pretensión de la entidad local de recurrir en casación la Sentencia dictada en apelación. En efecto, mediante Auto de 9 de junio de 1994, el alto Tribunal, si bien considera procesalmente inexacta la declaración anterior de la Audiencia, sostiene expresamente la falta de legitimación casacional del Ayuntamiento de Arrúbal conforme a lo dispuesto por el art. 1691 de la anterior LECiv, al no haber sido parte en el proceso, lo que determina la imposibilidad de que pueda preparar recurso de casación contra la Sentencia dictada por la Audiencia, a la vez que considera que de ser imputable a alguien la ausencia en el proceso de la entidad local, habría de serlo a las partes intervinientes en el mismo, pues en ningún momento de la primera o segunda instancia se alegó por los mismos la falta de litisconsorcio pasivo necesario.

Finalmente la propia Sentencia de 26 de noviembre de 1997 dictada en casación, ahora impugnada, en su fundamento de Derecho cuarto aborda 
nuevamente la cuestión al responder al motivo tercero de casación de ambos recursos fundado en la falta de litisconsorcio pasivo necesario, rechazando este extremo -entre otras consideraciones de índole procesalal considerarlo correctamente resuelto desde la primera instancia y al señalar textualmente a continuación que «la sentencia objeto del recurso de apelación alcanza, en sus efectos, a las partes demandadas, no aparece persona no demandada que quede afectada; se establece acertadamente la nulidad de unos acuerdos, aunque en los fundamentos de derecho se mencione uno de los acuerdos, notoriamente ilícito, como es la donación, aunque ésta no ha sido objeto directo de la acción ejercitada». A la luz del testimonio de las actuaciones remitidas a este Tribunal, se constata la existencia de la tramitación de un procedimiento específico declarativo de dominio y de subsanación y rectificación de inscripción registral seguido frente al Ayuntamiento ahora demandante como consecuencia de la discutida titularidad de las fincas de las que la entidad municipal se reclama donataria, incoado en autos de juicio declarativo de menor cuantía $n^{\circ}$ $344 / 1989$ por el Juzgado de Primera Instancia n. ${ }^{\circ} 2$ de Logroño.

De lo anteriormente expuesto cabe extraer como consecuencia relevante que, a los solos efectos que aquí interesan de valorar en este punto la existencia de la vulneración del derecho a la tutela judicial efectiva aducida por la demandante de amparo, el frustrado intento de la entidad demandante de comparecer en el proceso para interponer recurso de casación contra la Sentencia dictada por la Audiencia en apelación fue objeto de resolución motivada en Derecho, tanto por la propia Audiencia como más ampliamente por la Sala del Tribunal Supremo, sin que tal motivación, fruto del ejercicio de la función jurisdiccional que le es propia a los jueces y tribunales, pueda ser revisada por este Tribunal al no apreciarse en ella arbitrariedad, manifiesta irrazonabilidad o error de hecho patente, ni constituir dicha interpretación una simple proposición formalista o un entendimiento no razonable de las normas procesales vulneradora de las exigencias del principio de proporcionalidad (STC 61/2000, de 13 de marzo, F. 3, por todas) que la invaliden en su contraste constitucional.

b) Por lo que se refiere a la segunda de las cuestiones formuladas más arriba relativa a la indefensión presuntamente padecida por la entidad municipal al no haber sido llamada al proceso y haberse tramitado el mismo sin su conocimiento, la respuesta se muestra -si cabe- con mayor rotundidad. En primer lugar, ha de señalarse que conforme aprecia el Tribunal Supremo en su Sentencia ahora impugnada, ninguna de las partes intervinientes en el proceso postuló la comparecencia en el mismo de dicha entidad local, ni fue siquiera valorada tal posibilidad de oficio por ninguno de los órganos judiciales actuantes en ambas instancias, dada la 
naturaleza de la pretensión que se deducía en el procedimiento. Pero, en segundo lugar y sobre todo, es hecho de extraordinaria importancia a los efectos del presente pronunciamiento sobre la concurrencia en el presente caso de una verdadera indefensión material con relevancia constitucional -según se ha dejado expuesto- la constatación de que, frente a la insistente y contumaz afirmación reiterada en los escritos presentados ante este Tribunal por la corporación recurrente alegando la indefensión padecida por el desconocimiento del proceso, es lo cierto que, atendidas las circunstancias particulares que concurren en el presente caso, no sólo podría afirmarse razonablemente una presunción de conocimiento extraprocesal por la entidad municipal del proceso seguido (así en la reciente STC $73 / 2003$, de 23 de abril, F. 4), como sostiene en su escrito de alegaciones el Ministerio Fiscal, sino que, como pone de manifiesto el testimonio de las actuaciones remitidas a este Tribunal, se hallan numerosas y contundentes evidencias, no ya de un conocimiento extraprocesal por la hoy demandante, como sostienen en su escrito de alegaciones los actores del proceso civil, sino incluso de un propio conocimiento procesal del mismo desde su inicio en el año 1986, siendo siete años después (1993), tras haber recaído Sentencia en primera instancia y posteriormente la dictada en apelación por la Audiencia, desfavorable a sus intereses, cuando intenta el acceso a la casación la entidad local ahora recurrente». (Vid. f.j. 6).

Fallo: Se deniega el amparo solicitado por el Ayuntamiento de Arrúbal (La Rioja).

(Sentencia del Tribunal Constitucional n. ${ }^{\circ}$ 87/2003 (Sala Primera), de 19 mayo. BOE 10-06-2003. Ponente: R. García-Calvo y Montiel).

\section{ACTIVIDAD SANCIONADORA}

1. Recurso de amparo $n{ }^{\circ} 4680 / 2001$ contra el Decreto del Primer Teniente de Alcalde responsable de la rama de policía municipal, tráfico e infraestructuras del Ayuntamiento de Madrid de 19 de noviembre de 1998, por el que se impuso la sanción de suspensión de la licencia de autotaxi, y contra la resolución del Alcalde-Presidente del Ayuntamiento de Madrid de 6 de abril de 2000, por la que se desestimó el recurso de alzada formulado contra el mencionado Decreto; asi como contra la Sentencia del Juzgado de lo Contencioso-Administrativo $n .^{\circ} 16$ de Madrid de 23 de junio de 2001, desestimatoria del recurso contencioso-administrativo interpuesto contra dicha sanción. Considera el recurrente que la 
resolución administrativa impugnada vulneraría el principio de legalidad sancionadora (art. 25.1 CE ), por haber impuesto la sanción de suspensión temporal de la licencia de autotaxi con apoyo exclusivo en una Ordenanza municipal que carecería de la cobertura legal exigida constitucionalmente. El TC otorga el amparo.

«a) En primer lugar, como advierte el Ministerio Fiscal, es evidente que tampoco los preceptos de la Ley de Ordenación de los Transportes Terrestres invocados por la Sentencia del Juzgado de lo ContenciosoAdministrativo para entender que la sanción tenía la cobertura legal exigida por el art. 25.1 CE cumplen con las exigencias derivadas de este precepto constitucional. Las letras c) y f) del art. 7 LOTT establecen, respectivamente, que corresponde a los poderes públicos «promulgar las normas necesarias para la adecuada ordenación de los transportes terrestres, en desarrollo o en concordancia con la presente Ley»; y «ejercer las funciones de inspección y sanción en relación con los servicios y actividades de transportes terrestres». Se está aquí ante preceptos atributivos de competencias, pero no existe en estas normas criterio material alguno que sirviera para orientar y condicionar la valoración del Municipio al establecer tipos de infracciones a través de ordenanza municipal, conforme exige la doctrina sobre la flexibilización de la reserva de Ley del art. 25.1 CE «en materias donde, por estar presente el interés local, existe amplio campo para la regulación municipal» ( STC 132/2001, de 8 de junio, F. 6).

b) Por otra parte, ya en la STC 132/2001, de 8 de junio, F. 8 (relativa a otra sanción impuesta en aplicación de la mencionada Ordenanza del Ayuntamiento de Madrid) se declaró que para las infracciones graves la sanción de suspensión temporal de la licencia o autorización correspondiente «no encuentra precisa cobertura legal en los criterios sancionadores de la LOTT», pues dicha sanción está prevista sólo "para algunas concretas infracciones muy graves» (...)». (vid. f.j. 3).

Fallo: Se acuerda otorgar el amparo solicitado y, en consecuencia:

1 Reconocer el derecho del recurrente en amparo a la legalidad sancionadora (art. 25.1 CE)).

2. Declarar la nulidad del Decreto del Primer Teniente de Alcalde responsable de la rama de policía municipal, tráfico e infraestructuras del Ayuntamiento de Madrid de 19 de noviembre de 1998, por el que se impuso la sanción de suspensión de la licencia de autotaxi, y de la Resolución del Alcalde Presidente del Ayuntamiento de Madrid de 6 de abril de 2000, 
RESEÑA DE SENTENCIAS DEL TRIBUNAL CONSTITUCIONAL SOBRE LA ADMINISTRACIÓN LOCAL Y AUTONÓMICA...

por la que se desestimó el recurso de alzada formulado contra el mencionado Decreto; así como de la Sentencia del Juzgado de lo ContenciosoAdministrativo n. ${ }^{\circ} 16$ de Madrid de 23 de junio de 2001, desestimatoria del recurso contencioso-administrativo interpuesto contra dicha sanción.

(Sentencia del Tribunal Constitucional n. ${ }^{\circ}$ 193/2003 (Sala Primera), de 27 octubre. BOE 26-11-2003. Ponente: J. Delgado Barrio).

2. Recurso de amparo $n .^{\circ} 1571 / 2001$, contra el Decreto del Primer Teniente de Alcalde responsable de la rama de Policía Municipal, tráfico e infraestructuras del Ayuntamiento de Madrid, de 24 de febrero de 1999, por el que se impuso sanción de suspensión de licencia de autotaxi; asi como contra la Sentencia de la Sala de lo Contencioso-Administrativo (Sección Segunda) del Tribunal Superior de Justicia de Madrid, de 23 de enero de 2001, que desestimó el recurso de apelación interpuesto contra la Sentencia del Juzgado de lo Contencioso-Administrativo $n .^{\circ} 23$ de Madrid, de 9 de marzo de 2000, que desestimó el recurso contencioso-administrativo interpuesto frente a la mencionada resolución sancionadora.

Considera el recurrente, por una parte, que la resolución administrativa impugnada vulneraría el principio de legalidad sancionadora (art. 25.1 CE), por haber impuesto la sanción de suspensión temporal de la licencia de auto-taxi con apoyo exclusivo en una ordenanza municipal que carecería de la cobertura legal impuesta constitucionalmente. Por otra parte, el demandante de amparo imputa a las dos resoluciones judiciales que desestimaron el recurso contencioso-administrativo interpuesto dos vulneraciones adicionales de derechos fundamentales: del derecho a la igualdad en la aplicación de la Ley (art. 14 CE) y del derecho a la tutela judicial efectiva (art. 24.1 CE). El TC otorga el amparo solicitado.

«Es doctrina de este Tribunal, recientemente reiterada en la STC 52/2003, de 17 de marzo (F. 7), que «el derecho fundamental enunciado en el art. 25.1 CE incorpora la regla «nullum crimen nulla poena sine lege», extendiéndola incluso al ordenamiento sancionador administrativo, que comprende una doble garantía. La primera, de orden material y de alcance absoluto, tanto por lo que se refiere al ámbito estrictamente penal como al de las sanciones administrativas, que refleja la especial trascendencia del principio de seguridad en dichos ámbitos limitativos de la libertad individual y se traduce en la imperiosa exigencia de predeterminación normativa de las conductas ilícitas y de las sanciones correspondientes. La segunda es de carácter formal, y se refiere al rango necesario de las normas tipificadoras de aquellas conductas y reguladoras de estas 
sanciones, por cuanto, como este Tribunal ha señalado reiteradamente, el término «legislación vigente» contenido en dicho art. 25.1 CE es expresivo de una reserva de Ley en materia sancionadora (SSTC 61/1990, de 29 de marzo, F. 7; 60/2000, de 2 de marzo, F. 3; 25/2002, de 11 de febrero, F. 4 y 113/2002, de 9 de mayo, F. 3). A este respecto es preciso reiterar que en el contexto de las infracciones y sanciones administrativas el alcance de la reserva de Ley no puede ser tan riguroso como lo es por referencia a los tipos y sanciones penales en sentido estricto, y ello tanto por razones que atañen al modelo constitucional de distribución de las potestades públicas como por el carácter en cierto modo insuprimible de la potestad reglamentaria en determinadas materias, o bien, por último, por exigencias de prudencia o de oportunidad (STC 42/1987, de 7 de abril F. 2). En todo caso, el art. 25.1 CE exige la necesaria cobertura de la potestad sancionadora de la Administración en una norma de rango legal habida cuenta del carácter excepcional que presentan los poderes sancionatorios en manos de la Administración (SSTC 3/1988, de 21 de enero, F. 9 y 305/1993, de 25 de octubre, F. 3). De ahí que la reserva de Ley en este ámbito tendría una eficacia relativa o limitada (STC 177/1992, de 2 de noviembre, F. 2), que no excluye la colaboración reglamentaria en la propia tarea de tipificación de las infracciones y atribución de las correspondientes sanciones, pero sí que tales remisiones hicieran posible una regulación independiente y no claramente subordinada a la Ley (STC 83/1984, de 24 de julio, F. 4)».

Más concretamente, es de recordar la STC 132/2001, de 8 de junio, cuya doctrina fundamental puede sintetizarse así: a) La suspensión de la licencia de auto-taxi impuesta al ahora recurrente es, sin duda, «una sanción administrativa sometida a lo que prescribe el art. 25.1 CE» (F. 3); b) Ningún precepto constitucional prevé «la limitación de derechos constitucionales en un ámbito de actividad económica privada, aunque esté intervenida y reglamentada, como es la prestación de servicios de transporte en auto-taxi» (F. 4); c) La exigencia de Ley para la regulación de las infracciones y sanciones en las ordenanzas municipales, siempre que se aprueben por el Pleno del Ayuntamiento, «ha de ser flexible», aunque «esta flexibilidad no sirve, con todo, para excluir de forma tajante la exigencia de Ley» (F. 6)». (vid. f.j. 3).

«El derecho fundamental a la legalidad sancionadora (art. 25.1 CE), en relación con el principio de seguridad jurídica también garantizado constitucionalmente (art. 9.3 CE), exige que cuando la Administración ejerce la potestad sancionadora sea la propia resolución administrativa que pone fin al procedimiento la que, como parte de su motivación [la impuesta por los arts. 54.1 a) y 138.1 de la Ley de Régimen Jurídico de las Adminis- 
traciones Públicas y del Procedimiento Administrativo Común], identifique expresamente o, al menos, de forma implícita el fundamento legal de la sanción. Sólo así puede conocer el ciudadano en virtud de qué concretas normas con rango legal se le sanciona, sin que esté excluido, como acaba de exponerse, que una norma de rango reglamentario desarrolle o concrete el precepto o los preceptos legales a cuya identificación directa o razonablemente sencilla el sancionado tiene un derecho que se deriva del art. 25 CE.

En el caso que plantea la demanda de amparo, la resolución administrativa sancionadora sólo fundamentó la sanción que se imponía en los preceptos de la Ordenanza municipal de 1980 que regulan la infracción constatada y la sanción a ella vinculada, sin que, de forma implícita fuera posible identificar con la mínima seguridad razonable qué preceptos legales proporcionaban cobertura a los de rango reglamentario aplicados (...)

Desde la perspectiva del reparto de poderes entre la Administración y los órganos judiciales en el ámbito del ejercicio de la potestad sancionadora administrativa debe destacarse que, conforme a la regulación vigente de la misma, es a la Administración a la que está atribuida la competencia sancionadora y que a los órganos judiciales corresponde controlar la legalidad del ejercicio de esas competencias por la Administración. No es función de los jueces y tribunales reconstruir la sanción impuesta por la Administración sin fundamento legal expreso o razonablemente deducible mediante la búsqueda de oficio de preceptos legales bajo los que puedan subsumirse los hechos declarados probados por la Administración.

En el ámbito administrativo sancionador corresponde a la Administración, según el Derecho vigente, la completa realización del primer proceso de aplicación de la norma (que debe ser reconducible a una con rango de Ley que cumpla con las exigencias materiales del art. 25.1 CE), lo que implica la completa realización del denominado silogismo de determinación de la consecuencia jurídica: constatación de los hechos, interpretación del supuesto de hecho de la norma, subsunción de los hechos en el supuesto de hecho normativo y determinación de la consecuencia jurídica. El órgano judicial puede controlar posteriormente la corrección de ese proceso realizado por la Administración, pero no puede llevar a cabo por sí mismo la subsunción bajo preceptos legales encontrados por él, y que la Administración no había identificado expresa o tácitamente, con el objeto de mantener la sanción impuesta tras su declaración de conformidad a Derecho. De esta forma, el juez no revisaría la legalidad del ejercicio de la potestad sancionadora sino que, más bien, lo completaría» (Vid. f.j. 3). 
Fallo: Se acuerda otorgar el amparo solicitado y, en consecuencia:

$1^{\circ}$ Reconocer el derecho del recurrente en amparo a la legalidad sancionadora (art. 25.1 CE).

$2^{\circ}$ Declarar la nulidad del Decreto del Primer Teniente de Alcalde responsable de la rama de policía municipal, tráfico e infraestructuras del Ayuntamiento de Madrid, de 24 de febrero de 1999, por el que se impuso al recurrente sanción de suspensión de licencia de auto-taxi; así como de la Sentencia de la Sala de lo Contencioso-Administrativo (Sección Segunda) del Tribunal Superior de Justicia de Madrid, de 23 de enero de 2001, dictada en el recurso de apelación $n .^{\circ} 133 / 2000$, y de la Sentencia del Juzgado de lo Contencioso-Administrativo n. ${ }^{\circ} 23$ de Madrid, de 9 de marzo de 2000 .

(Sentencia del Tribunal Constitucional n. ${ }^{\circ}$ 161/2003 (Sala Primera), de 15 septiembre. BOE 9-10-2003. Ponente: J. Delgado Barrio).

3. Recurso de amparo $n .^{\circ} 727 / 2000$, promovido por la entidad Teresa Aranda Comunicaciones, SA (TACSA., contra la Sentencia del Juzgado de lo Contencioso-Administrativo ${ }^{\circ}{ }^{\circ} 22$ de Madrid, de 17 de enero de 2000, recaida en el procedimiento abreviado $n .^{\circ} 15 / 1999$ frente a la resolución dictada por el Concejal Delegado del Area de Hacienda del Excmo. Ayuntamiento de Madrid, por delegación del Alcalde, en el expediente sancionador $n .^{\circ} 70558932-8$, por incumplir el deber de identificar al conductor de un vehículo mal aparcado del que es titular la entidad demandante de amparo. Falta de emplazamiento personal por la Administración a la demandante pese a tener conocimiento del verdadero domicilio. Sanción por infracción de tráfico impuesta de plano. Derecho fundamental a ser informado de la acusación. El TC otorga el amparo.

«(...)El ejercicio de los derechos de defensa y a ser informado de la acusación en el seno de un procedimiento administrativo sancionador presupone, obviamente, que el implicado sea emplazado o le sea notificada debidamente la incoación del procedimiento, pues sólo así podrá disfrutar de una efectiva posibilidad de defensa frente a la infracción que se le imputa previa a la toma de decisión y, por ende, que la Administración siga un procedimiento en el que el denunciado tenga oportunidad de aportar y proponer las pruebas que estime pertinentes y de alegar lo que a su derecho convenga. En este sentido, el Pleno de este Tribunal en la STC 291/2000, de 30 de abril, ha declarado, con base en la referida doctrina constitucional sobre la extensión de las garantías del art. $24 \mathrm{CE}$ al procedimiento administrativo sancionador, que los posibles defectos en la noti- 
ficación o emplazamiento administrativo, cuando se trate, como en este supuesto acontece, de un acto administrativo sancionador, revisten relevancia constitucional desde la perspectiva del art. $24 \mathrm{CE}$ (F. 4). Y la citada Sentencia, en relación con un acto administrativo carente de carácter sancionador, resultando dicha doctrina aplicable a los actos administrativos sancionadores, se ha referido a la necesidad de que la Administración emplace a todos los interesados siempre que ello sea factible, por ser conocidos e identificables a partir de los datos que se deduzcan u obren en el expediente administrativo, debiendo concurrir los siguientes requisitos para que revista relevancia constitucional la falta de emplazamiento personal: en primer lugar, que el no emplazado tenga un derecho subjetivo o interés legítimo que pueda verse afectado por la resolución que se adopte; en segundo lugar, que el no emplazado personalmente haya padecido una situación de indefensión a pesar de haber mantenido una actitud diligente; y, por último, que el interesado pueda ser identificado a partir de los datos que obren en el expediente (FF. 5 y 13). (Vid. f.j. 3).

«La aplicación de la doctrina constitucional expuesta ha de conducir en este caso, como sostiene el Ministerio Fiscal, al otorgamiento del amparo solicitado.

Es claro que se cumplen los requisitos a los que nos hemos referido para considerar que la falta de emplazamiento personal de la entidad demandante de amparo tiene relevancia constitucional. Así es patente, en primer término, que la resolución sancionadora recaída en el procedimiento administrativo sancionador afecta a los derechos e intereses legítimos de la recurrente en amparo; y, en segundo término, que no cabe apreciar en ésta una falta de diligencia determinante de la situación de indefensión padecida, pues ningún dato existe en las actuaciones que permita afirmar que tuvo conocimiento del procedimiento administrativo sancionador antes de que hubiese concluido, al serle notificada la providencia de apremio, ni por la Administración en ningún momento se le ha reprochado falta de diligencia alguna a la demandante de amparo.

Y, por lo que se refiere al tercero de los requisitos aludidos, también debe de entenderse cumplido. En efecto, el examen de las actuaciones permite constatar que el requerimiento para identificar al conductor infractor del vehículo propiedad de la demandante de amparo, la incoación del expediente administrativo sancionador por incumplir dicha obligación legal y la sanción impuesta, únicos actos administrativos que se pretendieron notificar a la recurrente en amparo, se intentaron notificar a ésta en su anterior domicilio social, procediéndose seguidamente, al resultar infructuosas dichas notificaciones, a su notificación mediante edictos 
publicados en el «Boletín Oficial de la Comunidad de Madrid». Consta, asimismo, en las actuaciones que el cambio de domicilio social de la demandante de amparo se había producido casi dos años antes a aquel primer intento de notificación y que había sido inscrito en el Registro Mercantil, siendo precisamente a este último domicilio al que el Ayuntamiento dirige la notificación de la providencia de apremio, momento a partir del cual la demandante de amparo tuvo conocimiento del expediente administrativo sancionador que se había tramitado contra ella. Ha de concluirse, pues, que la Administración, al no emplazar personalmente a la demandante de amparo en el procedimiento administrativo sancionador pese a tener conocimiento, $\mathrm{o}$, al menos, evidente posibilidad de adquirirlo, del verdadero domicilio de aquélla, no ha actuado con la diligencia que le era exigible y ha generado a la recurrente en amparo, al impedirle ejercer el derecho de defensa en el procedimiento administrativo sancionador, una situación de indefensión constitucionalmente relevante.

De hecho la sanción se ha impuesto de plano a la demandante de amparo, esto es, sin respetar procedimiento contradictorio alguno y, por tanto, privándole de toda posibilidad de defensa durante la tramitación del procedimiento administrativo sancionador (STC 291/2000, de 30 de noviembre, F. 12). En tal sentido, este Tribunal ha declarado en la STC 18/1981, de 8 de junio), que los valores esenciales que se encuentran en la base del art. $24 \mathrm{CE}$ «no quedarían salvaguardados si se admitiera que la Administración... pueda incidir en la esfera jurídica de los ciudadanos imponiéndoles una sanción sin observar procedimiento alguno $\mathrm{y}$, por tanto, sin posibilidad de defensa previa a la toma de decisión», pues «la garantía del orden constitucional exige que el acuerdo se adopte a través de un procedimiento en el que el presunto implicado tenga oportunidad de aportar y proponer las pruebas que estime pertinentes y alegar lo que a su derecho convenga» (F. 3).

Ha de concluirse, pues, que, al haberse impuesto a la entidad recurrente en amparo una sanción sin procedimiento contradictorio alguno, la Administración ha vulnerado el art. $24 \mathrm{CE}$, por no respetar el derecho fundamental de la demandante de amparo a no ser sancionada si no es a través del correspondiente procedimiento en el que, con las modulaciones que procedan, se respeten las garantías que se deducen del mencionado precepto constitucional (STC 291/2000, de 30 de noviembre, F. 12).

Al no ser reparada dicha lesión por el órgano jurisdiccional, en cuya Sentencia se ha desestimado la pretensión de la recurrente en amparo al considerar que, al haberse dado ésta por notificada al recibir la providencia de apremio y promover el recurso contencioso-administrativo contra 
la sanción impuesta no podía ya impugnar las omisiones y defectos apreciados en la tramitación del procedimiento administrativo sancionador, el restablecimiento a la demandante de amparo en sus derecho fundamentales ha de conducir a extender también la declaración de nulidad a la Sentencia del Juzgado de lo Contencioso-Administrativo». (Vid. f.j. 4).

Fallo: Se acuerda estimar la demanda de amparo promovida por la entidad Teresa Aranda Comunicaciones, SA (TACSA) y, en su virtud:

$1^{\circ}$ Declarar vulnerados los derechos de la recurrente a la defensa y a ser informada de la acusación (art. 24.2 CE).

$2^{\circ}$ Restablecerla en sus derechos y, a tal fin, declarar la nulidad de la Resolución dictada por el Delegado del Area de Hacienda del Excmo. Ayuntamiento de Madrid, por delegación del Alcalde, en el expediente sancionador n. ${ }^{\circ} 70558932-8$, así como la de la Sentencia del Juzgado de lo Contencioso-Administrativo n. $^{\circ} 22$ de Madrid, de 17 de enero de 2000, recaída en el procedimiento abreviado n. $^{\circ}$ 15/1999.

(Sentencia del Tribunal Constitucional n. ${ }^{\circ}$ 54/2003 (Sala Segunda), de 24 marzo. BOE 16-04-2003. Ponente: V. Conde Martín de Hijas).

\section{PROPIEDADES PÚBLICAS}

1. Conflicto positivo de competencia promovido por el Consejo Ejecutivo de la Generalidad de Cataluña, en relación con el art. 33.3 del Reglamento General de Carreteras, aprobado por RD 1812/1994, de 2 septiembre: Construcción por el Estado de nuevas carreteras o variantes: aprobación definitiva de estudios informativos por la Administración del Estado: afección a planes de ordenación urbanística: prevalencia de la competencia estatal en materia de obras públicas de interés general sobre la autonómica de urbanismo: existencia de mecanismos de cooperación interadministrativa entre el Estado y las CC AA: no se vulneran las competencias de la Comunidad Autónoma en materia de urbanismo.

Fallo:

En atención a todo lo expuesto, el Tribunal Constitucional, ha decidido. 
Desestimar el conflicto positivo de competencia promovido por el Consejo Ejecutivo de la Generalidad de Cataluña contra el art. 33.3 del Reglamento general de carreteras, aprobado por Real Decreto 1812/1994, de 2 de septiembre.

(STC n. ${ }^{\circ}$ 151/2003 (Pleno), de 17 julio. Conflicto positivo de competencia n. ${ }^{\circ}$ 508/1995. Ponente: D. Pablo García Manzano).

\section{DERECHO PÚBLICO DE LA ECONOMÍA}

\section{A) Comercio}

1. Recursos de inconstitucionalidad promovidos por el Gobierno de Navarra en relación con determinados preceptos de la Ley 7/1996, de 15 enero, de ordenación del comercio minorista, y con los arts. 2 y 3 de la LO 2/1996, de 17 enero, complementaria de la ordenación del comercio minorista: Competencia del Estado: competencia exclusiva para establecer las bases y la ordenación general de la actividad económica general: competencias normativas y ejecutivas; incluye la materia de "defensa de la competencia»; Equipamientos comerciales de gran superficie: Definición y regulación de su instalación: normativa básica del Estado: no se vulneran competencias de las CCAA en las materias de comercio interior y urbanismo; Exigencia de un informe preceptivo y no vinculante del Tribunal de Defensa de la Competencia: no se vulneran las competencias de las CC AA si dicho informe se refiere a licencias comerciales especificas para grandes establecimientos cuando su instalación pueda alterar la libre competencia en un ámbito supraautonómico; Modalidades de venta: competencia de las CC AA para disciplinar determinados tipos de venta, siempre que se ciñan al espacio de las relaciones jurídico-públicas; competencia del Estado en materia de defensa de la competencia. Ejercicio: normativa básica que requiere a los comerciantes autorización administrativa de la Comunidad Autónoma y su inscripción en un registro público: vulneración de las competencias de las CC AA en materia de comercio interior: Venta de saldos: definición por la normativa básica: constitucionalidad: ejercicio por el Estado de su competencia en materia de defensa de la competencia: no se vulneran competencias de las CC AA en materia de comercio interior. Venta ambulante o no sedentaria: definición por la normativa básica del Estado: vulneración de las competencias de las CC AA en materia de comercio interior; Horarios comerciales: libre opción del legislador ordinario para establecer un régimen limitativo de los horarios comerciales u otro de libertad de horarios. Regulación por el Estado mediante LO: disconformidad con el principio de reserva mate- 
rial de las leyes orgánicas: tal regulación no tiene carácter orgánico: no se transfieren facultades a las CC AA al amparo del art. 150.2 CE. Infracciones y sanciones: Normativa básica: constitucionalidad: no se vulneran competencias de las CC AA; Competencias de la Comunidad Foral sobre comercio interior: competencia exclusiva sin perjuicio de la legislación estatal sobre defensa de la competencia y de acuerdo con las bases y la ordenación de la actividad económica general. Ordenación del comercio minorista: regulación por el Estado: vulneración de las competencias de la Comunidad Foral de Navarra en lo relativo a la exigencia a los comerciantes de una autorización administrativa de la Comunidad Autónoma y de su inscripción en un registro público para el ejercicio de determinadas modalidades de venta, así como en la definición de la venta ambulante o no sedentaria.

Fallo:

En atención a todo lo expuesto, el Tribunal Constitucional, ha decidido:

Estimar parcialmente el recurso de inconstitucionalidad interpuesto por la Comunidad Foral de Navarra contra determinados preceptos de la Ley 7/1996, de 15 de enero, de ordenación del comercio minorista y, en consecuencia:

$1^{\circ}$ Declarar que, entendido en los términos recogidos en el último párrafo del fundamento jurídico 4 de esta Sentencia, el inciso del art. 6.2 de la Ley, que establece como preceptivo el informe del Tribunal de Defensa de la Competencia, es constitucional.

$2^{\circ}$ Declarar inconstitucionales y nulos los arts. 37 y 53 de la Ley, salvo el inciso inicial de este último, según se precisa en el último párrafo del fundamento jurídico 7 de esta Sentencia.

$3^{\circ}$ Desestimar el recurso en todo lo demás.

[STC $n .{ }^{\circ}$ 124/2003 (Pleno), de 19 junio. Recursos de Inconstitucionalidad núms. 1254/1996 y 1255/1996. Ponente: $D^{a}$. Elisa Pérez Vera].

\section{B) Farmacias}

1. Recurso de inconstitucionalidad planteado por el presidente del Gobierno en relación con los arts. 4.3, 20, 23.1, 45 b) en relación con el 
46 de la Ley del Parlamento de Galicia 5/1999, de 21 mayo, de Ordenación Farmacéutica (Voto particular que formula el magistrado don Vicente Conde Martín de Hijas, al que se adhieren los magistrados don Pablo Cachón Villar y don Javier Delgado Barrio): Transmisión a otros farmacéuticos: prohibición aplicable a oficinas de farmacia adjudicadas mediante concurso: inconstitucionalidad: normativa contraria a la legislación básica del Estado que posibilita tal transmisión; Autorización administrativa para su funcionamiento: caducidad al cumplir el farmacéutico titular los 70 años de edad o en caso de fallecimiento: constitucionalidad: no se vulneran ni competencias del Estado ni derechos constitucionales; Competencia de la Administración autonómica para autorizar la apertura, acreditación y cierre de las unidades de radiofarmacia: constitucionalidad: funciones de carácter ejecutivo que no vulneran las competencias del Estado en materia de legislación sobre productos farmacéuticos; Dispensación de medicamentos a través de correo o de servicios de mensajería: constitucionalidad: no se vulneran las competencias del Estado en materia de legislación sobre productos farmacéuticos; Unidades de radiofarmacia de tipo II: regulación autonómica: inconstitucionalidad: vulneración de las competencias del Estado en materia de legislación sobre productos farmacéuticos.

Fallo:

En atención a todo lo expuesto, el Tribunal Constitucional, ha decidido:

$1^{\circ}$ Estimar parcialmente el recurso de inconstitucionalidad planteado por el Presidente del Gobierno frente a la Ley del Parlamento de Galicia $5 / 1999$, de 21 de mayo, de ordenación farmacéutica y, en consecuencia, declarar que son inconstitucionales y nulos los arts. 23.1 y 45 b) de dicha Ley.

$2^{\circ}$ Desestimar el recurso de inconstitucionalidad en todo lo demás.

(STC n. ${ }^{\circ}$ 152/2003 (Pleno), de 17 julio. Recurso de Inconstitucionalidad n. ${ }^{\circ}$ 3537/1999. Ponente: D. Vicente Conde Martín de Hijas).

2. Recursos de inconstitucionalidad promovidos por el presidente del Gobierno en relación con la Ley de la Comunidad Autónoma de Extremadura 3/1996, de 25 junio, de Atención Farmacéutica, y la Ley de la Castilla-La Mancha 4/1996, de 26 diciembre, de Ordenación del Servicio Farmacéutico, y por el Consejo de Gobierno de la Junta de Comunidades de Castilla-La Mancha en relación con la Ley 16/1997, de 15 abril, de 
RESEÑA DE SENTENCIAS DEL TRIBUNAL CONSTITUCIONAL SOBRE LA ADMINISTRACIÓN LOCAL Y AUTONÓMICA...

Regulación de los Servicios de las Oficinas de Farmacia (con voto particular que formula el magistrado don Pablo García Manzano): título competencial aplicable: «sanidad»: competencia del Estado para dictar la normativa básica: competencia de las CC AA para el desarrollo legislativo y la ejecución de la legislación básica del Estado; Legislación básica: Autorización de apertura de oficinas de farmacia: transmisibilidad a favor de otros farmacéuticos establecida por la legislación básica, aunque limitada a los términos y condiciones que establezca la normativa de las CC AA; Competencias de la Comunidad Autónoma de Extremadura: debe respetar la normativa básica del Estado en materia de sanidad; Autorización administrativa de apertura de oficinas de farmacia: intransmisibilidad: vulneración de la legislación básica en materia de sanidad: inconstitucionalidad; Caducidad: regulación autonómica: no se vulneran competencias del Estado ni derechos constitucionales al trabajo, al libre ejercicio de profesiones o a la libertad de empresa. Competencias de la Comunidad Autónoma de Castilla-La Mancha: debe respetar la normativa básica del Estado en materia de sanidad; Autorización administrativa para la instalación de nuevas oficinas de farmacia: intransmisibilidad: vulneración de la legislación básica en materia de sanidad: inconstitucionalidad; Caducidad: regulación autonómica: constitucionalidad: no se vulneran competencias del Estado ni derechos constitucionales al trabajo, al libre ejercicio de profesiones o a la libertad de empresa; Titularidad de oficinas de farmacia: exclusión de cotitularidad: inconstitucionalidad: vulneración de la legislación básica estatal en materia de sanidad; previsión autonómica de que cada farmacéutico sólo puede ser titular de una única oficina de farmacia: constitucionalidad: no se vulneran competencias estatales ni derechos de particulares o profesionales.

Fallo:

En atención a todo lo expuesto, el Tribunal Constitucional, ha decidido:

$1^{\circ}$ Estimar parcialmente el recurso de inconstitucionalidad $n .^{\circ}$ 3540/1996, planteado por el Presidente del Gobierno frente a la Ley de la Comunidad Autónoma de Extremadura 3/1996, de 25 de junio, de atención farmacéutica y, en consecuencia:

Declarar que son inconstitucionales y nulos el párrafo primero del art. 14 , en tanto impide toda clase de transmisibilidad de las oficinas de farmacia, y el párrafo primero de la disposición transitoria tercera de dicha Ley. 
Desestimar el recurso de inconstitucionalidad en todo lo demás.

$2^{\circ}$ Estimar parcialmente el recurso de inconstitucionalidad $\mathrm{n}^{\circ}$ 1492/1997, planteado por el Presidente del Gobierno contra la Ley de Castilla-La Mancha 4/1996, de 26 de diciembre, de ordenación del servicio farmacéutico $\mathrm{y}$, en consecuencia:

Declarar que son inconstitucionales y nulos el inciso «sobre la que no puede recaer cotitularidad» del art. 20.2, el art. 38.1, párrafo tercero, y la disposición transitoria segunda, párrafo primero, de dicha Ley.

Desestimar el recurso de inconstitucionalidad en todo lo demás.

$3^{\circ}$ Desestimar el recurso de inconstitucionalidad n. ${ }^{\circ} 3316 / 1997$, promovido por el Consejo de Gobierno de la Junta de Comunidades de Castilla-La Mancha frente a la Ley 16/1997, de 25 de abril, de regulación de los servicios de las oficinas de farmacia.

(STC n. ${ }^{\circ}$ 109/2003 (Pleno), de 5 junio. Recursos de Inconstitucionalidad núms. 1492/1997, 3316/1997 y 3540/1996. Ponente: D. Tomás S. Vives Antón).

\section{C) Industria: subvenciones públicas del Estado}

1. Conflictos positivos de competencias promovidos por el Consejo Ejecutivo de la Generalidad de Cataluña, en relación con la Orden del Ministerio de Industria y Energía, de 25-04-1997, por la que se aprueban las bases reguladoras y la convocatoria para la concesión de ayudas en el trienio 1997/1999 en relación con la Iniciativa de Apoyo a la Tecnología, la Seguridad y la Calidad Industrial (ATYCA), y con la Orden de 2504-1997, por la que se aprueban las bases reguladoras y convocatoria para la concesión de ayudas de la Iniciativa de Apoyo a la Tecnología, la Seguridad y la Calidad Industrial (ATYCA), para el Programa Tecnológico de Investigación y Desarrollo Energético y para las áreas de tecnologías para el transporte y de tecnologías y aplicación para la sociedad de la información del Programa de Fomento de la Tecnología industrial: Programa de Fomento de la Tecnología Industrial: subvenciones públicas de la Administración del Estado: Títulos competenciales aplicables: en su mayor parte «industria»: aplicación del título «investigación cientifica y técnica» en lo referido a los proyectos y programas de investigación; Delimitación competencial general: en el caso de subvenciones relacionadas con la investigación científica y técnica, el Estado tiene competen- 
RESEÑA DE SENTENCIAS DEL TRIBUNAL CONSTITUCIONAL SOBRE LA ADMINISTRACIÓN LOCAL Y AUTONÓMICA...

cia exclusiva para regular en su plenitud las condiciones de otorgamiento de las subvenciones y su tramitación administrativa; en el caso de las subvenciones encuadradas en el título «industria», el Estado puede consignar subvenciones de fomento en sus presupuestos generales, especificando su destino y regulando sus condiciones esenciales de otorgamiento, pero debe territorializar las partidas presupuestarias entre las CCAA en los mismos presupuestos o en un momento posterior: a las CC AA les corresponde la gestión de estos fondos; Competencia del Estado para regular las condiciones generales de otorgamiento: objeto, definiciones, ámbito de aplicación, acciones y actividades subvencionables, beneficiarios, ámbito temporal, periodo subvencionable, líneas tecnológicas de actuación preferente, plazo de presentación de solicitudes, criterios de evaluación de solicitudes, cuantía máxima de las ayudas, aplicaciones presupuestarias e inversiones en proyectos tecnológicos para el medio ambiente industrial...; Competencia de las CC AA para regular las cuestiones referidas a solicitudes, subsanación y mejora de la solicitud, estudio y evaluación de las solicitudes, propuesta y aceptación de subvenciones, concesión de la subvención, plazo de resolución de los procedimientos, pago de las subvenciones concedidas, pago anticipado de subvenciones, justificación de la realización del proyecto, convenios con otras CC AA y otras cuestiones; Programa Tecnológico de Investigación y Desarrollo Energético: aplicación del título competencial «investigación científica y técnica»: competencia del Estado para la regulación completa de su régimen jurídico, tramitación, concesión y pago por el Estado; Para estudios de viabilidad técnica previos a actividades de investigación industrial, actividades de desarrollo precompetitivas y proyectos de demostración industrial: aplicación del título «energía»o «régimen energético»: competencia del Estado para regular las condiciones básicas de otorgamiento de las ayudas y competencia de las CC AA para el desarrollo legislativo y gestión de las subvenciones, previa territorialización de los fondos estatales entre las CC AA. Programa de Calidad y Seguridad Industrial: subvenciones públicas del Estado: Título competencial aplicable: «industria»: corresponde al Estado, en virtud de su competencia exclusiva en materia de bases y coordinación de la planificación general de la actividad económica, establecer las normas básicas de ordenación del otorgamiento de estas ayudas: competencia de las CC AA para su gestión y pago.

Fallo:

En atención a todo lo expuesto, el Tribunal Constitucional, ha decidido: 
$1^{\circ}$ Estimar parcialmente el conflicto positivo de competencia $\mathrm{n}^{\mathrm{o}}$ $3757 / 1997$, promovido frente a la Orden de 25 de abril de 1997, por la que se aprueban las bases reguladoras y la convocatoria para la concesión de ayudas en el trienio 1997/1999 en relación con la Iniciativa de Apoyo a la Tecnología, la Seguridad y la Calidad Industrial (ATYCA), declarando que vulneran las competencias de la Generalidad de Cataluña los puntos noveno, décimo, undécimo, decimoquinto, decimosexto, decimoséptimo, decimoctavo, decimonoveno, vigésimo, vigesimoprimero, disposición adicional $1^{\mathrm{a}}$, disposición adicional $2^{\mathrm{a}}$ y Anexo 3 de la misma, en lo relativo a las ayudas que hemos incardinado en la materia de industria en los fundamentos jurídicos 7, 15 y 16, de esta Sentencia.

$2^{\circ}$ Estimar parcialmente el conflicto positivo de competencia $n^{\circ}$ $3187 / 1999$ planteado contra la Orden de 4 de marzo de 1999, del Ministerio de Industria y Energía, por la que se convocan ayudas en el marco de la Orden de 25 de abril de 1997, por la que se aprueban las bases reguladoras y convocatoria para la concesión de ayudas de la Iniciativa de Apoyo a la Tecnología, la Seguridad y la Calidad Industrial (ATYCA), para el Programa Tecnológico de Investigación y Desarrollo Energético y para las áreas de tecnologías para el transporte y de tecnologías y aplicación para la sociedad de la información del Programa de Fomento de la Tecnología industrial, declarando que vulneran las competencias de la Generalidad de Cataluña los puntos octavo, décimo, undécimo (apartados 2, 4, 5, 6, 7 y 8), duodécimo, decimotercero y Anexo 2, en lo relativo a las ayudas que hemos encuadrado en las materias de industria y de régimen energético en los fundamentos jurídicos 7 y 13 de esta Sentencia.

$3^{\circ}$ Desestimar los conflictos positivos de competencia en todo lo demás.

[STC n. ${ }^{\circ}$ 175/2003 (Pleno), de 30 septiembre. Conflictos positivos de competencia núms. 3187/1997 y 3757/1997. Ponente: D. Eugeni Gay Montalvo].

\section{RECURSOS NATURALES}

1. Recurso de inconstitucionalidad promovido por el presidente del Gobierno en relación con diversos preceptos de la Ley de la Comunidad Autónoma de Extremadura 8/1995, de 27 abril, de pesca: Pesca fluvial y protección de los ecosistemas: competencia autonómica exclusiva: a ella se suma la competencia de desarrollo legislativo y ejecución de la legislación básica en materia de medio ambiente: debe tener en cuenta 
RESEÑA DE SENTENCIAS DEL TRIBUNAL CONSTITUCIONAL SOBRE LA ADMINISTRACIÓN LOCAL Y AUTONÓMICA...

las competencias del Estado en las materias de recursos y aprovechamientos hidráulicos y de medio ambiente. Presas, diques y otras obras hidráulicas ya existentes: normativa autonómica que impone la construcción de escalas o pasos que faciliten el acceso de peces a los distintos tramos del curso del agua: invasión de la competencia estatal sobre el dominio público hidráulico. Nuevas instalaciones de presas, diques y otras obras hidráulicas: normativa que exige a los concesionarios de aprovechamientos hidráulicos la construcción de escalas que faciliten el paso de los peces: no se invade la competencia estatal sobre el dominio público hidráulico. Caudal mínimo: deber de los concesionarios de los aprovechamientos hidráulicos de dejarlo circular: no se vulneran las competencias del Estado en materia hidráulica: la Comunidad Autónoma no se atribuye la fijación del caudal mínimo. Rejillas: deber de su colocación y mantenimiento por los concesionarios de aprovechamientos hidráulicos en los cauces de derivación para que se impida el paso de los peces: no existe vulneración de las competencias del Estado en materia de aprovechamientos hidráulicos. Modificación de la composición de la vegetación de las orillas y márgenes y extracción de plantas acuáticas: sujeción a autorización autonómica: medida complementaria de protección del recurso pesquero: no existe vulneración de la competencia estatal sobre el dominio público hidráulico. Extracción de piedras existentes en los cauces y acumulación de residuos: prohibición por ley autonómica: vulneración de la competencia estatal en las materias de medio ambiente y aguas. Abandono o vertido de residuos o sustancias que alteren las condiciones de las masas de agua: prohibición por la Comunidad Autónoma: vulneración de la competencia estatal para dictar la legislación básica en materia de medio ambiente. Obstáculos, empalizadas o barreras: prohibición de su construcción con la finalidad de encauzar las aguas y obligar a los peces a seguir una dirección determinada: prohibición por la normativa autonómica: no hay vulneración de las competencias del Estado. Navegación en zonas señalizadas donde se entorpezca la pesca o se perturbe la tranquilidad de la fauna silvestre: prohibición por la normativa autonómica: constitucionalidad: no se vulneran las competencias del Estado. Infracciones y sanciones: regulación autonómica: inconstitucionalidad de las infracciones que interfieran en el ejercicio de competencias estatales concurrentes.

Fallo:

En atención a todo lo expuesto, el Tribunal Constitucional, ha decidido: 
Estimar parcialmente el recurso de inconstitucionalidad promovido por el Presidente del Gobierno contra la Ley de Extremadura 8/1995, de 27 de abril, de pesca, y en consecuencia:

$1^{\circ}$ Declarar que los arts. 27.1; 28; 31; y 63 c) 13 son contrarios al orden constitucional de competencias y, por tanto, nulos.

$2^{\circ}$ Desestimar el recurso en todo lo demás.

(STC n. ${ }^{\circ}$ 123/2003 (Pleno), de 19 junio. Recurso de Inconstitucionalidad n. ${ }^{\circ}$ 2988/1995. Ponente: D. Tomás S. Vives Antón). 